3

4

5

\title{
Seismic Performance of a Pile-Supported Wharf: Three-Dimensional Finite Element Simulation
}

\author{
Lei $\mathrm{Su}^{1}$, Jinchi Lu ${ }^{2}$, Ahmed Elgamal ${ }^{3^{*}}$, and Kandiah Arulmoli ${ }^{4}$
}

Abstract

Considerable three-dimensional (3D) effects are involved in the seismic performance of pilesupported wharves. Such effects include the pile-to-pile interaction mechanisms as dictated by the behavior of the surrounding soil. This interaction might be further affected by potential ground slope settlement/heave, and the constraint of pile connectivity along the relatively rigid wharf deck. In order to capture a number of these salient response characteristics, a 3D finite element (FE) study is conducted herein. The prototype system motivating this study is presented, along with the corresponding numerical details. A realistic multi-layer soil profile is considered, with interbedded relatively soft/stiff strata. Effect of the resulting seismically-induced ground deformation on the pile-supported wharf system is explored. Specific attention is drawn to the noteworthy potential changes in axial force due to variation in pile embedment depth, and the ground slope deformation. The analysis technique as well as the derived insights are of significance to general pile-wharf-ground system configurations.

Keywords: Wharf; Pile; Seismic; Earthquake; Port; Finite Element

1. Visiting Researcher, Dept of Structural Eng., University of California, San Diego, La Jolla, CA 92093-0085

2. Associate Project Scientist, Dept of Structural Eng., Univ. of California, San Diego, La Jolla, CA 92093-0085

3* Professor, Dept of Structural Eng., University of California, San Diego, La Jolla, CA 92093-0085

Corresponding Author; Tel. 858 822-1075, Fax. 858 534-1310, email: elgamal@ucsd.edu

4. Principal, Earth Mechanics Inc., 17800 Newhope Street, Suite B, Fountain Valley, CA 92708 


\section{Introduction}

Seaports are among the large-scale constructed facilities that are particularly vulnerable to damage and loss of function due to seismic activity (Akai et al. 1997; Werner et al. 1997; URS 2008; Mahoney et al. 2008; Brunet et al. 2012; Percher et al. 2013; Edge et al. 2013). In the U.S., port operations are generally reliant on pile-supported wharf structures (Tsinker 2004; Donahue et al. 2005). Damage to such structures has been observed in many recent seismic events, including the 1989 Loma Prieta and the 2010 Haiti earthquakes (EQE 1989; Werner 1998; Green et al. 2011; Werner et al. 2011). This highlights the need for further understanding of the seismic soil-structure interaction (SSI) response characteristics of such wharf-ground systems (Yan et al. 2004; Arulmoli et al. 2008; Lai et al. 2009).

A large number of reported numerical studies have been concerned with idealized twodimensional (2D) seismic response models of the wharf and surrounding ground (e.g., Roth et al. 2003; Roth and Dawson 2003; Dodds et al. 2004; Smith et al. 2004; Zmuda and Arulmoli 2004). To optimize the underwater bulkhead configuration, Yan et al. (2004) performed 2D FLAC static and dynamic soil-structure interaction analyses for the Port of Los Angeles Berth 145-146 Upgrade. A similar modeling approach was adapted to predict the seismic response of wharf structures at the Ports of Oakland and Los Angeles (Na et al. 2009; Dickenson et al. 2014). Arulmoli et al. (2004) carried out a 2D dynamic finite element (FE) DYNAFLOW analysis of a wharf-dike-backland system, investigating the pile pinning effects. Using OpenSees, Yang et al. (2012) conducted 2D FE simulations to develop fragility curves for a typical wharf structure. Employing advanced structural and soil modeling procedures, Shafieezadeh et al. (2012a) performed 2D nonlinear plane-strain seismic analyses. The simulated results showed that the pile-deck connection is a vulnerable location, and batter piles were found to be susceptible to large tensile axial forces. More recently, a fully nonlinear 2D FE study was conducted 
(Chiaramonte 2011; Chiaramonte et al. 2013) exploring the seismic performance of marginal wharves with conventional and improved pile-deck connection conditions. In this idealization, the piles were represented by nonlinear fiber section beam-column elements with prestressing steel. The pile elements were connected to the 2D soil mesh using nonlinear $p-y, t-z$, and $Q-z$ spring relationships. System response was assessed including crane damage and port downtime for three different hazard levels.

In order to more accurately incorporate plan irregularities, interaction of adjacent wharf sections, and pile-to-pile interaction considerations, three-dimensional (3D) numerical studies have been conducted. Takahashi (2003) employed a 3D FE mesh to analyze results of an idealized pilesupported wharf centrifuge model. Donahue et al. (2004) investigated the Port of Oakland Berth 24/25 recorded seismic response using Winkler-type nonlinear soil springs (El Naggar et al. 2005; Allotey and El Naggar 2008; El Ganainy and El Naggar 2009). The resulting response was found to be strongly dependent on the defined spring properties. A similar 3D soil spring modeling approach was employed by Doran et al. (2015) in a push-over seismic evaluation study. Addressing liquefaction, Shafieezadeh et al. (2012b) conducted 3D nonlinear studies of a typical pile-supported wharf. The numerical model employed nonlinear fiber section beamcolumn elements for the deck and the piles, and soil macro-elements to capture the forcedeformation of the coupled soil-pile system. The results showed that a $2 \mathrm{D}$ wharf representation may not fully account for involved 3D response characteristics.

The study reported herein (Su et al. 2016) employs a full 3D FE simulation framework, in order to capture and further elucidate a number of salient characteristics associated with the pileground and pile-to-pile interaction mechanisms. As such, the actual SSI of pile-ground geometric configuration is captured, without need for the above-mentioned 2D idealizations, related to definition of soil-springs that connect the pile beam elements to the surrounding soil mesh. A 

is considered. The FE computations were performed using OpenSees (McKenna et al. 2000), a nonlinear analysis platform for simulating seismic response of structural and geotechnical systems (Elgamal et al. 2008, 2009; Lu et al. 2011).

The following sections of this document outline: i) specifics and model properties of the wharfground system, ii) details of the employed FE modeling techniques, iii) results of the conducted numerical simulations, and iv) insights derived from the study. Finally, a number of conclusions are presented and discussed.

\section{Computational Framework}

All simulations were conducted using the open source computational platform OpenSees (http://opensees.berkeley.edu, McKenna et al. 2000). This platform allows for developing applications to simulate the performance of structural and geotechnical systems subjected to static and seismic loading.

Implemented in OpenSees (Yang 2000; Yang and Elgamal 2002) is an analysis framework for saturated soil response as a two-phase material following the $u-p$ formulation of Chan (1988) and Zienkiewicz et al. (1990), where $u$ is displacement of the soil skeleton, and $p$ is pore pressure. This implementation is based on the following assumptions: small deformation and rotation, solid and fluid density remain constant in time and space, porosity is locally homogeneous and constant with time, soil grains are incompressible, and solid and fluid phases are accelerated equally. Hence, the soil layers are represented by effective-stress fully coupled solid-fluid brick elements, seamlessly capable of accounting for soil deformations and the associated potential changes in pore-pressure (Lu 2006). 
The employed soil constitutive models (Parra 1996; Yang and Elgamal 2002; Elgamal et al. 2003) were developed based on the multi-surface-plasticity theory (Prevost 1978, 1985). In employing these models, the shear stress-strain backbone curve was represented by the hyperbolic relationship with the shear strength based on triaxial compression (reached at a shear strain of 12\%). As such, soil is simulated by the implemented (Yang et al. 2008) OpenSees materials PressureIndependMultiYield and PressureDependMultiYield.

The FE matrix equation is integrated in time using a single-step predictor multi-corrector scheme of the Newmark type (Chan 1988; Parra 1996) with time integration parameters $\gamma=0.6$ and $\beta=$ 0.3025. For each time step, the solution is obtained using the modified Newton-Raphson approach with Krylov subspace acceleration (Carlson and Miller 1998; Mazzoni et al. 2006). On this basis, the initial tangent stiffness of the system (after application of gravity) is used for all steps and iterations to achieve the prescribed tolerance (normalized displacement increment less than $\left.10^{-4}\right)$. Finally, a relatively low level of stiffness proportional damping $($ coefficient $=0.003)$ is employed to enhance the numerical system stability, with the main damping emanating from the soil nonlinear shear stress-strain hysteresis response (Kramer 1996).

\section{Piles and Soil-Pile Interface}

The piles and deck are simulated by 3D nonlinear fiber-section and elastic beam column elements, respectively (Mazzoni et al. 2006). To represent the geometric space occupied by the pile, essentially rigid beam-column links $\left(E I=10^{4}\right.$ times the linear $E I$ of the pile $)$ are used normal to the pile vertical axis (Elgamal et al. 2008). The 3D brick elements representing the soil are connected to the pile geometric configuration at the outer nodes of these rigid links (Law and Lam 2001) using zerolength elements and the OpenSees equalDOF translation constraint (Yan 2006; Elgamal et al. 2008). These zerolength (zeroLengthSection) elements are used to: i) axially connect the rigid link to the adjacent soil node, and ii) provide for skin-friction yield 
shear force along the soil-pile interface (according to the assumed soil-pile friction angle and adhesion) limited by:

$$
F_{\text {skin friction }}=\left(c_{\mathrm{A}}+\sigma \tan \delta\right) \cdot l \cdot h / N
$$

where $l$ is the pile perimeter; $h$ is the center to center contributing height (according to the adjacent soil element heights), $\delta$ is the soil-pile friction angle, $c_{A}$ is the soil-pile adhesion, $\sigma$ is the lateral effective stress, and $N$ is the number of zeroLengthSection elements along the pile perimeter.

\section{Finite Element Model}

The employed pile-supported structural and ground configuration (Fig. 1) is typical of such facilities in the U.S. Southwest (e.g., Container Wharves at the Port of Los Angeles, California). As shown in Fig. 1a, this $317.2 \mathrm{~m}$ long wharf structure is composed of a reinforced concrete deck supported on six rows of vertical pre-cast concrete piles (rows A through $\mathrm{F}$ as shown in Fig. 1). Along its longitudinal direction (Fig. 1a), the wharf consists of a large number of identical 3D $6.1 \mathrm{~m}$ thick segments (3D slices). As such, a representative 3D slice may be selected for computational simulation of the wharf's seismic response. In this idealization (Fig. 2): i) seismic excitation/response will be investigated only in the transverse landside-waterside direction, and as such ii) the free-field boundary conditions at both longitudinal ends (Fig. 1a) are implicitly assumed to be of a relatively minor influence (for the purpose of this study). In essence, this 3D FE model bears similarity to the ubiquitous 2D plane-strain analysis approach (with idealizations as discussed above), but naturally permits for a more accurate representation of the actual 3D geometric pile layout and associated pile-ground-pile interaction considerations.

Based on the above, the finite element mesh of the pile-supported wharf model (Fig. 2) includes 9649 3D brick elements. Along the longitudinal waterside and landside mesh boundaries, 2D plane strain soil columns of large size and depth (not shown) are included (Chiaramonte et al. 
2013). These columns, at an adequate distance away from the wharf structure to minimize boundary effects (Fig. 2), efficiently reproduce the desired shear beam free-field response at these locations.

\subsection{Ground Configuration}

As shown in Fig. 3, the inclination angle of the slope is about 31 degrees. The FE ground model is $230 \mathrm{~m}$ long and $6.1 \mathrm{~m}$ wide (Figs. 2 and 3). Total depth of the soil layers is $33.5 \mathrm{~m}$ and $53.8 \mathrm{~m}$ at the waterside (the far right side in Fig. 3) and the landside (the far left side in Fig. 3), respectively. The soil domain (EMI 2001) is idealized into four units (Fig. 3) including 9 sublayers as well as the dike structure (Table 1). For simplicity, the topmost soil unit I, is represented by vertical nodal forces (surcharge stress of $82 \mathrm{kPa}$ ) which also account for the 48 $\mathrm{kPa}$ container stacking and handling stresses (Fig. 3). Soil unit II (Table 1) is divided into three sub-layers consisting of upper loose to medium dense silty sand (IIA), middle dense to very dense sand and silty sand (IIB), and lower medium dense silty sand/clayey sand interbedded with layers of silt and clay (IIC). Soil unit III is subdivided into three cohesive sub-layers, with stiffness and strength increasing as a function of depth. Soil unit IV contains two sub-layers, an upper dense sand/clayey sand (IVA), and a lower very dense silty sand (IVB). Water table is at the top of sub-layer IIA (Fig. 3). To more easily attain a stable slope configuration under gravity loading, the dike material included a nominal cohesion of $20 \mathrm{kPa}$ (Table 1). Additional detailed information about the sub-layer conditions is presented in EMI (2001).

In view of the cohesionless strata having relatively high friction angles (Table 1), liquefaction is not the primary concern (EMI 2001, 2006). As such, for computational convenience, permeability for all soil strata was set to the high value of $1 \mathrm{~m} / \mathrm{s}$, mimicking drained conditions. Nevertheless, the numerical framework as reported herein can be used to explore liquefaction scenarios when warranted. 


\subsection{Wharf Structure}

In this pile-supported wharf model (Fig. 2), there are 16 prestressed reinforced concrete piles in 6 rows. The piles are octagonal in cross-section, each $0.61 \mathrm{~m}$ across. All piles are $42 \mathrm{~m}$ in length except for the short $18 \mathrm{~m}$ pile E2 (Fig. 2) that was included for added lateral seismic resistance (EMI 2001). The long piles are embedded $4.5 \mathrm{~m}$ deep into the very dense base sand stratum (layer IVB in Fig. 3).

The prestressed reinforced concrete piles are modeled using 3D fiber-section nonlinear forcebased beam-column elements. Original geometry and discretization of the pile cross section into concrete and steel fibers (Blandon 2007) are shown in Fig. 4 (a) and (b) with core and cover concrete inside and outside the shear reinforcement/stirrups, respectively. In this fiber section, the core and cover concrete are approximated by the OpenSees Concrete01 Kent-Scott-Park model (Kent and Park 1971; Scott et al.1982; Mander et al. 1988) with degraded linear unloading/reloading stiffness. Table 2 summarizes the concrete constitutive model parameters. Stress-strain response under cyclic loading is shown in Fig. 4 (c) and (d).

The prestressing steel is modeled using the OpenSees Steel02 Giuffrè-Menegotto-Pinto model (Giuffrè and Pinto 1970; Mengotto and Pinto 1973; Filippou et al. 1983) with isotropic strain hardening and an imposed axial initial stress. Input parameters and stress-strain response are presented in Table 3 and Fig. 4(e), respectively. Fig. 4 (f) shows the moment-curvature response of the prestressed pile cross section under the influence of different axial force levels. It can be seen that the moment capacity is enhanced with the increase in the acting compressive axial force. 


\subsection{Boundary and Loading Conditions}

192

193

194

195

196

197

198

199

200

201

202

203

204

205

206

207

208

209

210

211

212

213

214

The landside and waterside lateral boundaries are located away from pile-supported wharf structure (Figs. 2 and 3). Along the $6.1 \mathrm{~m}$ apart transverse symmetry planes (Fig. 2), no out of plane motion is allowed. The loading conditions are implemented in a staged fashion as follows:

1) For the soil mesh only (Fig. 2), gravity is applied to activate the initial static state with: i) linear elastic soil properties (Poisson's ratio of 0.4 ), ii) nodes on both side planes of the model (waterside and landside) fixed against transverse translation, iii) nodal forces on top of sub-layer unit IIA applied due to weight of soil unit I and container-stacking surface pressures (about 82 $\mathrm{kPa}$ ), and iv) water table specified along top of soil layer IIA on the landside with related water pressure and nodal forces specified on the waterside. At the end of this step, the static soil state is imposed, and displacements are re-set to zero using the OpenSees function InitialStateAnalysis.

2) For the structural wharf and pile elements: i) the pile fiber section nonlinear force-based beam-column elements are defined with the base nodes fixed. A static analysis is performed to impose the prestress axial load (Chiaramonte, 2011), and ii) the pile rigid link and associated zero length elements are introduced, along with the wharf deck elements. The zero length element nodes are fixed, and pile base fixity is removed. At this stage, the soil and the structure meshes are fully defined, but are not connected yet.

3) The full soil-structure mesh is assembled by: i) the zero length element nodes are connected to the corresponding adjacent soil nodes using the OpenSees equalDOF constraint, and ii) fixity constraints on the zero length element nodes are removed.

4) Soil properties are switched from elastic to plastic (Table 1) and convergence is achieved.

5) Self-weight of piles and deck elements are applied.

6) For the shaking phase (purely in the transverse direction), a base motion with a relatively high peak acceleration was employed, in order to introduce a significant level of nonlinear response. 
215 This motion (Fig. 5) was simply taken as that of the 1994 Northridge earthquake ground surface

216 Rinaldi Receiving Station record (Component S48W), scaled down to half amplitude (as the

217 within ground motion at depth). In this representation, free-field motion along the longitudinal

218 waterside and landside boundaries is generated by the included 2D plane strain soil columns

219 mentioned above. On this basis, dynamic excitation is imparted.

\section{Computed Response}

\subsection{Landside and Waterside Lateral Boundaries: Free Field Seismic Response}

As mentioned above, in order to reproduce free field conditions along the FE mesh lateral

223 boundaries, large size plane strain soil columns were introduced. The soil profiles at the waterside and the landside lateral boundaries were employed for that purpose. Figs. 6 and 7 show the corresponding computed relative displacement and absolute acceleration response. Noting the elevation (Fig. 3) of the low strength clay stratum (IIIA), along the landside boundary,

227 permanent displacement of the layers above is larger (Fig. 6a), and peak acceleration is relatively 228 low (Fig. 6b). Along the waterside boundary, peak accelerations are high and permanent displacements are low (Fig. 7). As such, compared to the base input motion (Fig. 5), significant

230 reduction in the peak acceleration occurs along the landside boundary (Fig. 6b), while peak 231 acceleration is amplified along the waterside boundary (Fig. 7b). Permanent displacement is 232 accumulated mainly during the $2.5-3.5 \mathrm{~s}$ time interval due to the large fling-motion pulse in the 233 base input acceleration (Fig. 5), reaching about $0.09 \mathrm{~m}$ at the landside boundary (Fig. 6a).

\subsection{Slope Response}

235 Fig. 8 shows the displacement and acceleration response at different depths at location P (Fig. 3).

236 The response pattern is quite similar to that at landside mesh boundary (Fig. 6). However, peak 237 and permanent displacement at location $\mathrm{P}$ are greater (Fig. 8), due to further down-slope motion 
towards to the waterside. Shear stress-strain at this location is shown in Fig. 9. Large permanent

239 shear strain is particularly evident in the low strength clay layer at $33.1 \mathrm{~m}$ elevation (IIIA in Fig.

240 3). The large shear strain excursion (Fig. 9) correspond to the observed jump in permanent 241 displacement as shown in Fig. 8a.

\subsection{Deck Response}

243 Similar to the underlying ground slope (Fig. 8), the wharf deck displays a permanent 244 displacement of about $0.4 \mathrm{~m}$ (Fig. 10a). Acceleration (Fig. 10b) is also close to that of the ground 245 surface near this location as shown in Fig. 8b.

\section{Deformation}

247 In the following, the computed results will be discussed at two specific time instants (Fig. 10) 248 during the shaking phase: i) the time step at maximum deck displacement (labeled as max time 249 step), and ii) the time step at the end of shaking (labeled as final time step).

\subsection{Ground Deformation}

251 Fig. 11 shows the deformed mesh at the max time step (contour fill shows transverse/vertical 252 displacement). As discussed earlier, it can be seen that the largest lateral displacements occur in 253 the upper layers (Figs. 11a and b), in large part due to the shear deformation (Fig. 9) of the weak 254 layer (IIIA, Fig. 3). In the zone of the ground slope (Fig. 11), significant lateral deformations 255 extend deeper into the ground. Fig. 11b shows that the maximum slope lateral displacement 256 occurs near the dike toe. Generally, the slope moves along with the embedded piles towards to waterside. Away from the slope, the lower soil layers (IIIB, IVA, and IVB) undergo relatively 258 minor lateral displacements (Fig. 11). Along with the slope lateral deformations, notable slump and heave variations occur along the slope and at its toe (Fig. 11c). 
Fig. 12 depicts the deformed mesh at the final time step. Overall, the displacement pattern is quite similar to that of the max time step, with some additional permanent vertical deformations.

\subsection{Pile and Slope Lateral Deformation}

Figs. 13 and 14a display a close-up of the pile and slope surface deformations. Generally, it can be seen that the pile displacements are significantly affected by the pattern of slope deformation (Fig. 13). Displacement at the final time step is smaller than that at the max time step (Figs. 13 and 14a), presumably due to absence of inertial loading at the end of the shaking event. In addition, a decrease in the pile displacement profiles is noted, mainly for the landside piles D-F (Fig. 14a). Deeper into the ground, pile displacement is virtually the same for both time steps (Fig. 14a). While the rigid wharf deck dictates that all piles experience the same lateral top displacement, it may be noted that the corresponding lateral slope displacement is somewhat larger near the toe (Fig. 13). In terms of vertical deformation, it can be seen that the slope surface moved downwards near the crest (near Pile row F) and upwards near toe (near Pile row A). However, the deck motion was essentially horizontal (Fig. 13), indicating that the piles remained firmly anchored within the deep foundation stratum (IVB).

\section{Pile Response and Discussion}

\subsection{Shear Force and Bending Moment}

Figs. 14b and 15a display the response profiles of pile shear force and bending moment at the max and final time steps. In the free pile spans above the ground surface, shear forces are low, and bending moments change linearly. Peak moments are seen to occur in the vicinity of the displacement profile inflexion points (Fig. 14a). With more compliant soil response near the ground surface (Fig. 14a), the highest moments are seen at depth, prominently in the landside 
282 piles D1-F1. While keeping the same pattern, substantial residual moments remain at the end of 283 this shaking event (Fig. 15a).

284 Along with the moment profile, Fig. 15b displays the pile curvature response profile at the max 285 and final time steps. By far, curvature values are highest around the weak clay layer IIIA zone 286 (Fig. 3). When referenced to the pile cross-sectional moment-curvature response (Fig. 4f), Figs. $28715 \mathrm{a}$ and $15 \mathrm{~b}$ indicate that significant yielding below the ground surface is predicted under this 288 strong shaking scenario.

\subsection{Axial Forces}

\subsubsection{Overall Response}

Before shaking, the computed self-weight axial force profiles are shown in Fig. 16a. All piles are 292 seen to be under compressive forces throughout (i.e., negative axial force). Below the deck, the axial forces add up to represent the imposed wharf deck own weight. Axial forces above the ground slope increase in a uniform stepwise fashion (Fig. 16a), due to pile self-weight. Below the ground, changes are dictated by the interaction between the foundation, the underlying slope, and involved soil strata. Below the weak layer (IIIA), positive (upward) skin friction is prevalent.

297 All piles essentially display the same axial force at the tip, including the short pile E2 (Fig. 16a). Displayed in a different way, Fig. 16b shows the change in axial forces, referenced to the static 299 state (Fig. 16a). The remarks below concerning axial force changes are directly driven by the 300 slope vertical deformation pattern as depicted earlier in Fig. 13, generally with settlement near 301 the crest and heave near the toe. Of prominence in this depiction, are the additional compressive 302 forces throughout the profile in the landside piles $\mathrm{C} 1-\mathrm{F} 1$, and the tensile forces near the toe in 303 piles $\mathrm{A} 1$ and $\mathrm{B} 1$. 
Fig. 17a shows the axial force distribution at the max time step. At the top (Fig. 17a), all piles remain under compression except for the short pile (E2) which undergoes a substantial tensile force. Below the ground slope surface (Fig. 17a), tensile forces occur in pile rows A-C, with substantial values in the waterside pile rows A and B. Low tensile tip forces are noted for all piles including pile E2 (Fig. 17a). In particular, at the landside pile row F, substantial negative downdrag skin friction prevails throughout much of the pile length.

The final pile axial force profiles are shown in Fig. 17b. In view of the increased slope settlement at this point, the piles experience the downdrag scenario observed earlier in pile row F. Minor tensile forces are now only seen in the waterside pile row A.

\subsubsection{Influence of Short Pile (E2)}

Compared to the compressive state of the short pile (E2) before shaking (Fig. 16a), tensile forces occurred virtually throughout the pile length as shown at the max and final time steps (Fig. 17). Such a change is a direct consequence of the pile being embedded only within the upper ground strata of the slope that have moved downwards as shown in Fig. 13. This tensile force is substantial, and in turn exerts added compression on the surrounding piles.

Related to this short pile scenario, additional computational simulations were conducted (Su et al. 2016) in which: (case A) the pile E2 was extended to match the embedment depth of all other piles, and (case B) the short pile E2 was removed entirely from the mesh. In both cases, for this particular shaking scenario, there were only minor changes in the lateral displacement, shear, moment, and curvature responses reported above (Figs. 14-15). Axially, the self-weight profile (Fig. 16a) was also similar, with slight decrease (case A) and slight increase (case B) in the top compressive forces mainly within the piles of row E (as expected). During the shaking event, contrasted with the short E2 pile tensile force scenario (Fig. 17a), a visible reduction in the row E pile top compressive forces occurred in both cases A and B (Figs. 18a and b). As such, while the 
short $\mathrm{E} 2$ is a contributor to the resistance of lateral inertial forces, potential permanent

329 deformations in the underlying slope might cause undesirable down drag-induced tensile forces.

\section{Summary and Conclusions}

A 3D finite element analysis framework was presented in an attempt to address a number of salient features associated with the seismic response of wharf-ground systems. In particular, it was shown that response of the piles, all rigidly connected along the wharf deck and embedded into the ground slope, was substantially dictated by the resulting soil deformation mechanisms.

The wharf system and the corresponding numerical analysis details were discussed. Moment, shear, and axial pile forces resulting from the seismically-induced ground deformation were explored. The numerical framework and the insights derived from this study are of relevance to general wharf-pile-ground configurations. As observed in this study, driven by the occurrence of permanent slope deformations, the following conclusions can be drawn:

1) In the conducted study, the accumulated lateral permanent deformation of the ground was driven in large part by presence of a relatively weak soil stratum. Local slope-driven horizontal and vertical deformations were also a contributing factor.

2) Irrespective of the free span of each pile above the ground slope, the pattern and magnitude of lateral deformation was rather similar in all rows. As such, significant stress concentrations were not evident in the landside piles with the short free span, as might result from inertial wharf deck loads with little or no down-slope soil displacement.

3) Motivated by the associated vertical slope movement and deformation, substantial additional axial forces may occur. These forces are a consequence of the overall slope spatial deformation pattern and the integral monolithic nature of the wharf deck and pile support system. Such coupled response mechanism is potentially of importance and might not be adequately captured 
351 by the conventional $p-y / t-z$ soil springs approach. Consequently, further attention to axial forces

352 is warranted, even in this scenario of strictly vertical piles with no batter.

353 4) Reduction in compression, or even occurrence of tensile forces in the piles, might significantly

354 decrease the stiffness and strength of the reinforced concrete piles, reducing the available axial-

355 load dependent flexural capacity and resistance to lateral deformations.

356 5) Due to the underlying permanent slope deformations, the short pile E2 was found to undergo 357 significant down drag-induced tensile forces. In return, the surrounding piles endured additional 358 compressive load as a reaction to these tensile forces. As such, approaches to alleviate the 359 consequences of this short E2 pile configuration might be of value.

\section{Acknowledgements}

361 The presented research was funded partially by the U.S. National Science Foundation (NSF 362 award CMMI-1201195). This support is gratefully acknowledged. 


\section{References}

Akai K, Bray JD, Christian JT, et al. (1997) Geotechnical reconnaissance of the effects of the January 17, 1995, Hyogoken-Nanbu earthquake, Japan. UCB/EERC-95/01, University of California, Berkeley.

Allotey N and El Naggar MH (2008) A Numerical study into lateral cyclic nonlinear soil-pile response. Canadian Geotechnical Journal 45(9):1268-1281.

Arulmoli K, Johnson GS, Yin P, et al. (2008) Geotechnical considerations and soil-structure interaction: Proposed ASCE standards for seismic design of piers and wharves. Geotechnical Earthquake Engineering and Soil Dynamics IV, Sacramento, CA, pp 1-10

Arulmoli K, Martin GR, Gasparro MG, et al. (2004) Design of pile foundations for liquefactioninduced lateral spread displacements. GeoTrans 2004, Los Angeles, California, pp 1673-1681.

Blandon C (2007) Seismic analysis and design of pile supported wharves. PhD Thesis, Rose School Pavia.

Brunet S, Llera JC, Jacobsen A, et al. (2012) Performance of port facilities in Southern Chile during the 27 February 2010 Maule Earthquake. Earthquake Spectra 28(S1):553-579.

Carlson NN, Miller K (1998) Design and application of a gradient weighted moving finite element code I: In one dimension. SIAM Journal on Scientific Computing, 19(3):728-765.

Chan AHC (1988) A unified finite element solution to static and dynamic problems in geomechanics. $\mathrm{PhD}$ Thesis, University College of Swansea.

Chiaramonte MM (2011) An analysis of conventional and improved marginal wharves. Master Thesis, University of Washington.

Chiaramonte MM, Arduino P, Lehman DE, and Roeder CW (2013) Seismic analyses of conventional and improved marginal wharves. Earthquake Engineering \& Structural Dynamics 42(10):1435-1450. 
387 Dickenson SE, Yang S, Schwarm D, et al. (2014) Seismic performance analysis of pile388 supported wharves subjected to long-duration ground motions. Proceedings of SMIP14 Seminar 389 on Utilization of Strong-Motion Data, Berkeley, CA, pp 63-82.

390 Dodds AM, Martin GR, Arulmoli K, et al. (2004) Lifeline upgrade for a wharf in soft ground. 391 GeoTrans 2004, Los Angeles, California, pp 1739-1746.

392 Donahue MJ, Dickenson SE, Miller TH, et al. (2005) Implications of the observed seismic 393 performance of a pile-supported wharf for numerical modeling. Earthquake Spectra 21(3):617394634.

395 Donahue MJ, Dickenson SE, Miller TH, and Yim SC (2004) Comparison of 3D modeling to 396 recorded seismic response for a pile supported wharf. Ports conference 2004, Houston, Texas, pp $397 \quad 1-10$.

409 Elgamal A, Yang Z, Parra E, and Ragheb A (2003) Modeling of cyclic mobility in saturated 410 cohesionless soils. International Journal of Plasticity 19(6):883-905. 
411 El Ganainy H and El Naggar MH (2009) Efficient 3D nonlinear Winkler model for shallow

412 foundations. Soil Dynamics and Earthquake Engineering 29(8):1236-1248.

413 El Naggar, MH, Shayanfar, MA, Kimiaei, M, and Aghakouchak, AA (2005) Simplified BNWF 414 model for nonlinear seismic response analysis of offshore piles. Canadian Geotechnical Journal $415 \quad 42(2): 365-380$.

416 EMI (2001) Final geotechnical and seismic analyses and design report berth 100 container wharf, 417 west basin Port of Los Angeles, San Pedro, California. Prepared by Earth Mechanics, Inc. (EMI) 418 submitted to Port of Los Angeles, California.

419 EMI (2006) Port-wide ground motion and Palos Verdes fault study Port of Los Angeles, 420 California. Prepared by Earth Mechanics, Inc. (EMI) submitted to Port of Los Angeles, 421 California.

422

423

424

EQE (1989) The October 17, 1989 Loma Prieta Earthquake. Prepared by EQE Engineering Inc.

\section{Report, October 1989.}

Filippou FC, Popov EP, Bertero VV (1983) Effects of bond deterioration on hysteretic behavior of reinforced concrete joints. Report EERC 83-19. Earthquake Engineering Research Center, University of California, Berkeley.

Green RA, Olson SM, Cox BR, et al. (2011) Geotechnical aspects of failures at Port-au-Prince Seaport during the 12 January 2010 Haiti Earthquake. Earthquake Spectra 27(S1):43-65.

Giuffrè A, Pinto P (1970) II comportamento del cemento armato per sollecitazioni cicliche di forte intensità. Giornaledel Genio Civile 5(1):391-408 (Italian).

Kent DC, Park R (1971) Flexural members with confined concrete. Journal of the Structural Division 97(7):1969-1990.

Kramer, S. L. (1996). Geotechnical earthquake engineering. Prentice-Hall Civil Engineering and Engineering Mechanics Series, Upper Saddle River, NJ: Prentice Hall. 
Lai C, Jaradat OA, Weismair M (2009) Seismic design criteria for pile-supported wharves at the port of Long Beach. TCLEE 2009: Lifeline Earthquake Engineering in a Multihazard Environment, pp 1-10.

Law HK, Lam IP (2001) Application of periodic boundary for large pile group. Journal of Geotechnical and Geoenvironmental Engineering 127(10):889-892.

Lu J (2006) Parallel finite element modeling of earthquake site response and liquefaction. $\mathrm{PhD}$ Thesis, University of California, San Diego.

Lu J, Elgamal A, Yan L, et al. (2011) Large-scale numerical modeling in geotechnical earthquake engineering. International Journal of Geomechanics 11(6):490-503.

Mahoney M, Francis M, Kennard D (2008) Performance of the Kawaihae harbor port facility resulting from the October 2006 earthquake. Solutions to Coastal Disasters Congress 2008, Turtle Bay, Oahu, Hawaii, pp 925-938.

Mander JB, Priestley MJ, Park R (1988) Theoretical stress-strain model for confined concrete. Journal of Structural Engineering 114(8):1804-1826.

Mazzoni S, McKenna F, Scott MH, et al. (2006) OpenSees command language manual. Pacific Earthquake Engineering Research Center, University of California, Berkeley, CA.

McKenna F, Fenves G, Scott M (2000) Open System for Earthquake Engineering Simulation (OpenSees). Pacific Earthquake Engineering Research Center, University of California, Berkeley, CA.

Mengotto M, Pinto P (1973) Method of analysis for cyclically loaded reinforced concrete plane frames including changes in geometry and non-elastic behavior of elements under combined normal force and bending. IABSE Symposium on Resistance and Ultimate Deformability of Structures Acted on by Well-Defined Repeated Loads, Final Report. 
Na UJ, Chaudhuri SR, Shinozuka M (2009) Performance evaluation of pile-supported wharf under seismic loading. Technical Council on Lifeline Earthquake Engineering Conference, Oakland, California, pp 1032-1041.

Parra E (1996) Numerical modeling of liquefaction and lateral ground deformation including cyclic mobility and dilation response in soil systems. PhD Thesis, Rensselaer Polytechnic Institute.

Percher M, Bruin W, Dickenson SE, et al. (2013) Performance of port and harbor structures impacted by the March 11, 2011 Great Tohoku Earthquake \& Tsunami. $13^{\text {th }}$ Triennial International Conference, Seattle, Washington, pp 610-619.

Prevost JH (1978) Plasticity theory for soil stress-strain behaviour. Journal of the Engineering Mechanics Division 104(5):1177-1194.

Prevost JH (1985) A simple plasticity theory for frictional cohesionless soils. Soil Dynamics and Earthquake Engineering 4(1):9-17.

Roth W, Dawson E (2003) Analyzing the seismic performance of wharves, Part 2: SSI analysis with non-linear, effective-stress soil models. Advancing Mitigation Technologies and Disaster Response for Lifeline Systems, pp 395-404.

Roth W, Dawson E, Mehrain M, et al. (2003) Analyzing the seismic performance of wharves, Part 1: Structural-engineering approach. $6^{\text {th }}$ US Conference and Workshop on Lifeline Earthquake Engineering, pp 385-394.

Scott B, Park R, Priestley M (1982) Stress-strain behavior of concrete confined by overlapping hoops at low and high strain rates. ACI Journal Proceedings 79(1):13-27.

Shafieezadeh A, DesRoches R, Rix GJ, et al. (2012a) Seismic performance of pile-supported wharf structures considering soil-structure interaction in liquefied soil. Earthquake Spectra 28(2):729-757. 
Shafieezadeh A, DesRoches R, Rix GJ, et al. (2012b) Three-dimensional wharf response to farfield and impulsive near-field ground motions in liquefiable soils. Journal of Structural Engineering 139(8):1395-1407.

Smith D, Naesgaard E, Kullmann H (2004) Seismic design of a new pile and deck structure adjacent to existing caissons founded on potentially liquefiable ground in Vancouver, BC. Proceedings of $13^{\text {th }}$ World Conference on Earthquake Engineering, Vancouver, BC, Paper No. 2138.

Su L, Lu J, Elgamal A (2016) Seismic performance of a pile-supported wharf: three-dimensional finite element simulation. Report No. SSRP-16/04, Dept of Structural Engineering, University of California, San Diego, La Jolla, CA (in preparation).

Takahashi A (2003) Seismic performance evaluation of pile-supported wharf by 3D finite element analysis. Proceedings of the $12^{\text {th }}$ Asian regional conference on soil mechanics and geotechnical engineering, Singapore, pp 245-248.

Tsinker GP (2004) Port engineering: planning, construction, maintenance, and security. John Wiley \& Sons, New Jersey.

URS (2008) Final report port facility analysis for Kawaihae Harbor, October 15, 2006, Kiholo Bay Earthquake. Contract No. HSFEHQ-06-D-0162, Prepared for Federal Emergency Management Agency, Department of Homeland Security.

Werner SD (1998) Experience from past earthquakes, seismic guidelines for ports. Technical council on lifeline earthquake engineering of ASCE, Monograph No.12, Chapter 2.

Werner SD, Dickenson SE, Taylor CE (1997) Seismic risk reduction at ports: Case studies and acceptable risk evaluation. Journal of waterway, port, coastal, and ocean engineering 123(6):337346. 
505 Werner SD, McCullough N, Bruin W, et al. (2011) Seismic performance of port de Port-au-

506 Prince during the Haiti Earthquake and post-earthquake restoration of Cargo Throughput.

507 Earthquake Spectra 27(S1):387-410.

508 Yan L (2006) Sensor data analysis and information extraction for structural health monitoring.

509 PhD Thesis, University of California, San Diego.

510 Yan L, Arulmoli K, Weismair W, et al. (2004) Seismic soil-structure interaction analyses of an

511 underwater bulkhead and wharf system. GeoTrans 2004, Los Angeles, California, pp 547-555.

512 Yang CSW, DesRoches R, Rix GJ (2012) Numerical fragility analysis of vertical-pile-supported

513 wharves in the western United States. Journal of Earthquake Engineering 16(4):579-594.

514 Yang Z (2000) Numerical modeling of earthquake site response including dilation and 515 liquefaction. PhD Thesis, Columbia University.

516 Yang Z, Elgamal A (2002) Influence of permeability on liquefaction-induced shear deformation.

517 Journal of Engineering Mechanics 128(7):720-729.

518 Yang Z, Lu J, Elgamal A (2008) OpenSees soil models and solid-fluid fully coupled elements

519 user manual. University of California, San Diego.

520 Zienkiewicz OC, Chan AHC, Pastor M, et al. (1990) Static and dynamic behavior of soils: a 521 rational approach to quantitative solutions. I. fully saturated problems. Proceedings of the Royal 522 Society London, Series A, Mathematical and Physical Sciences 429(1877):285-309.

523 Zmuda R, Arulmoli K (2004) Use of displacement piles to improve slope stability at port of Los 524 Angeles Berth 100 Wharf. Ports 2004, Port Development in the Changing World, Houston, 525 Texas, pp 1-10. 
Table 1 Soil parameters

\begin{tabular}{|c|c|c|c|c|c|c|c|}
\hline \multicolumn{2}{|c|}{ Soil unit } & Soil description & $\begin{array}{c}\text { Density } \\
\left(\mathrm{t} / \mathrm{m}^{3}\right)\end{array}$ & $\begin{array}{l}\text { Friction } \\
\text { angle } \\
\text { (Degree) }\end{array}$ & $\begin{array}{l}\text { Shear } \\
\text { modulus } \\
(\mathrm{MPa})\end{array}$ & $\begin{array}{c}\text { Bulk } \\
\text { modulus } \\
(\mathrm{MPa})\end{array}$ & $\begin{array}{c}\text { Cohesion } \\
(\mathrm{kPa})\end{array}$ \\
\hline \multicolumn{2}{|c|}{ I } & Sandy fill (above GWT*) & 1.92 & & & & \\
\hline \multirow{3}{*}{ II } & A & Loose marine sand & 1.92 & 32 & 100 & 469 & 0 \\
\hline & $\mathrm{B}$ & Dense marine sand & 2.00 & 36 & 151 & 703 & 0 \\
\hline & $\mathrm{C}$ & Medium dense marine sand & 2.00 & 34 & 127 & 591 & 0 \\
\hline \multirow{3}{*}{ III } & $\mathrm{A}$ & Soft to stiff lagoonal clay & 1.76 & 0 & 26 & 122 & 80 \\
\hline & $\mathrm{B} 1$ & Stiff lagoonal clay & 1.84 & 0 & 43 & 200 & 108 \\
\hline & $\mathrm{B} 2$ & Stiff lagoonal clay & 1.84 & 0 & 84 & 391 & 135 \\
\hline \multirow{2}{*}{ IV } & $\mathrm{A}$ & Dense lakewood-San Pedro sand & 2.00 & 36 & 186 & 868 & 0 \\
\hline & $\mathrm{B}$ & Very dense lakewood-San Pedro sand & 2.08 & 38 & 279 & 1300 & 0 \\
\hline- & Dike & Quarry run & 2.24 & 45 & 141 & 1363 & 20 \\
\hline
\end{tabular}

* GWT is Ground Water Table

Note: For each involved soil layer, the soil-pile friction angle $\delta$ and/or the soil-pile adhesion $c_{A}$ are assumed equal to the corresponding friction angle and/or cohesion, respectively. 
Table 2 Constitutive model parameters for concrete used in fiber section

\begin{tabular}{lcc}
\hline Concrete material parameters & Core concrete & Cover concrete \\
\hline Compressive strength, $f_{c}^{\prime}(\mathrm{MPa})$ & -74.9 & -49.0 \\
Strain at compressive strength, $\varepsilon_{c}$ & -0.005 & -0.002 \\
Crushing strength, $f_{c u}(\mathrm{MPa})$ & -63.0 & 0 \\
Strain at crushing strength, $\varepsilon_{c u}$ & -0.018 & -0.004 \\
\hline
\end{tabular}

Table 3 Constitutive model parameters for steel used in fiber section

\begin{tabular}{lcc}
\hline Steel material parameters & Value \\
\hline Yield strength, $f_{y}(\mathrm{MPa})$ & & 1490 \\
Elastic modulus, $E(\mathrm{MPa})$ & & $2.04 \times 10^{5}$ \\
Prestressing stress, $\sigma_{\text {Init }}(\mathrm{MPa})$ & & 1062 \\
Strain-hardening ratio, $b$ & & 0 \\
\hline \multirow{2}{*}{ Parameters to control transition } & $\mathrm{R} 0$ & 18 \\
from elastic to plastic branches & $\mathrm{cR} 1$ & 0.925 \\
& $\mathrm{cR} 2$ & 0.15 \\
\hline & $\mathrm{a} 1$ & 0.007 \\
& $\mathrm{a} 2$ & 1 \\
Isotropic hardening parameter & $\mathrm{a} 3$ & 0.007 \\
& $\mathrm{a} 4$ & 1 \\
\hline
\end{tabular}




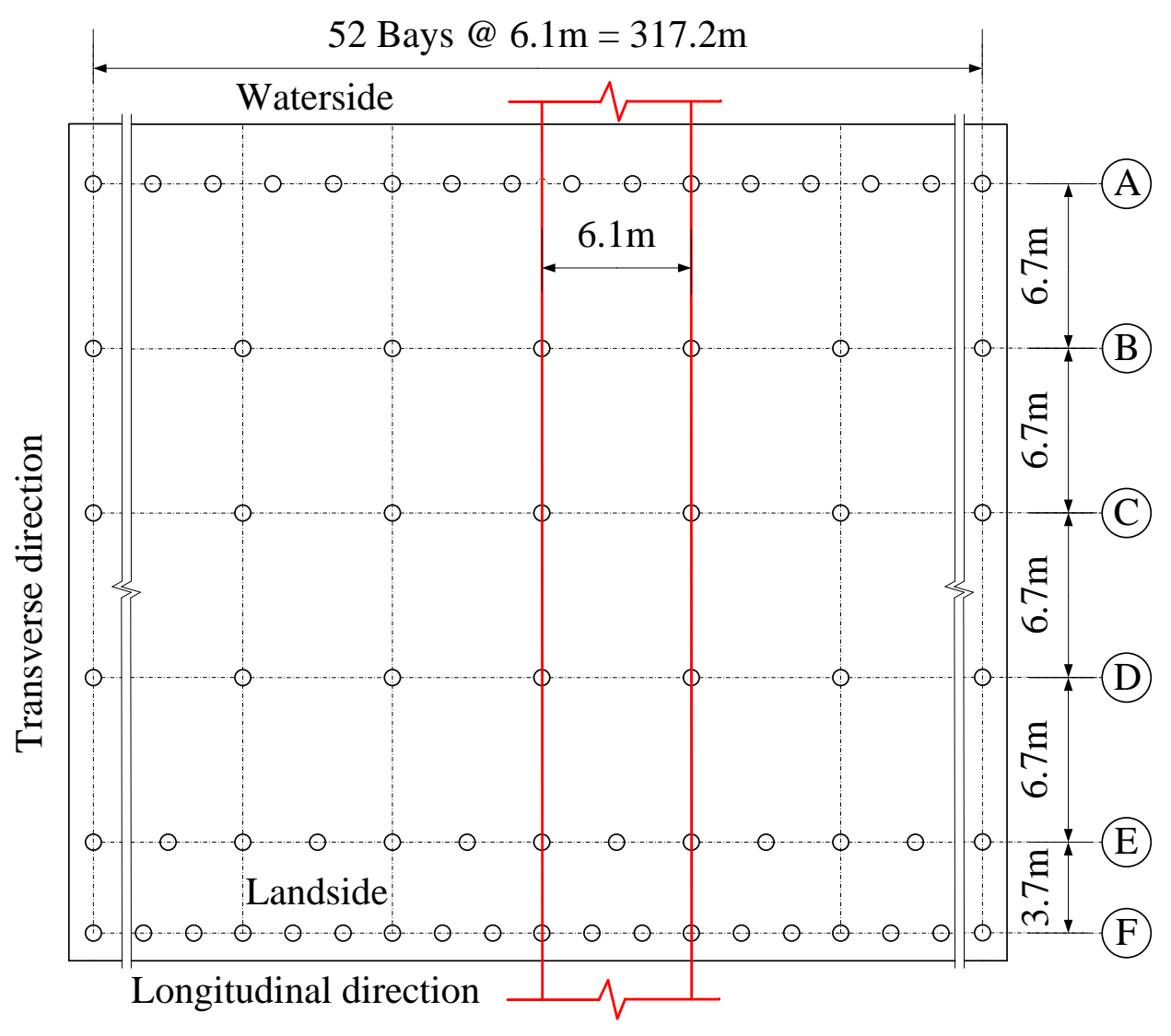

(a) Plan view

(F) E

(D)

(C)

(B)

(A)

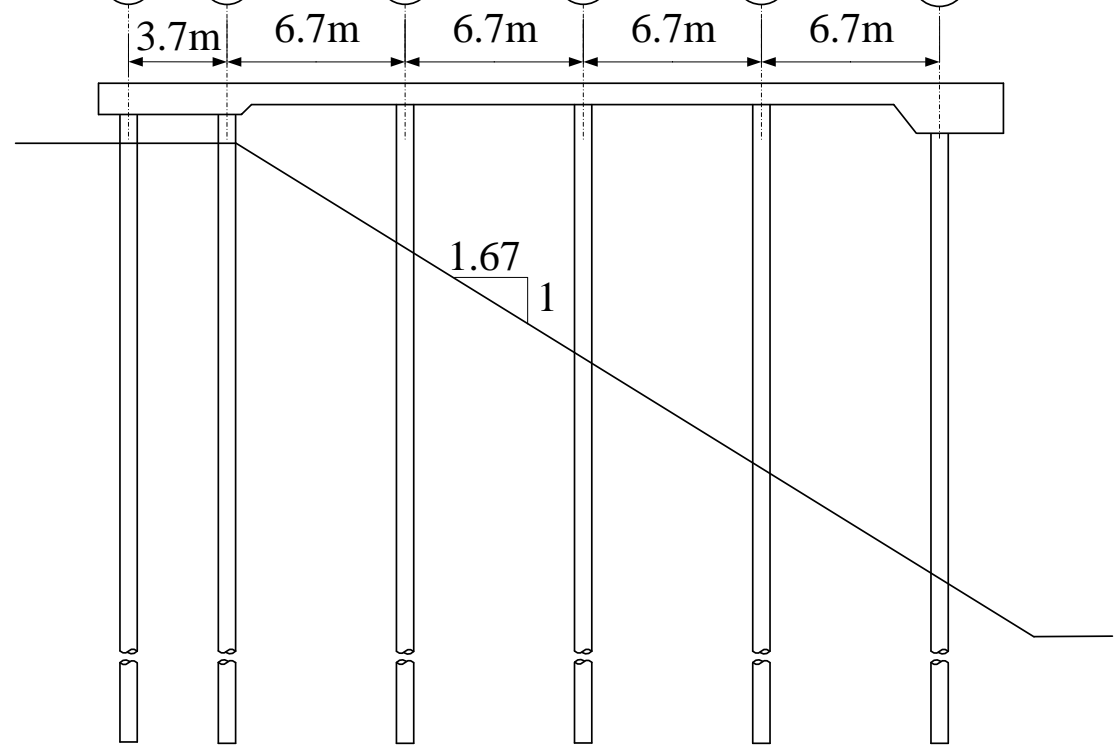

(b) Side view (Transverse cross-section)

Fig. 1 Wharf configuration 


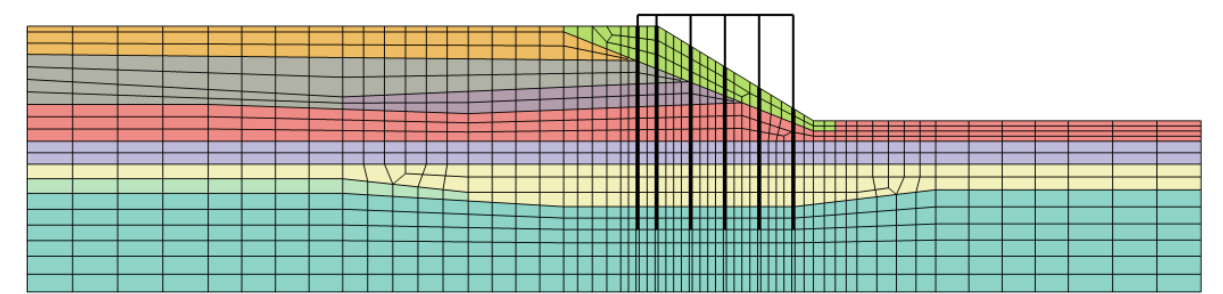

(a) Transverse (side) view

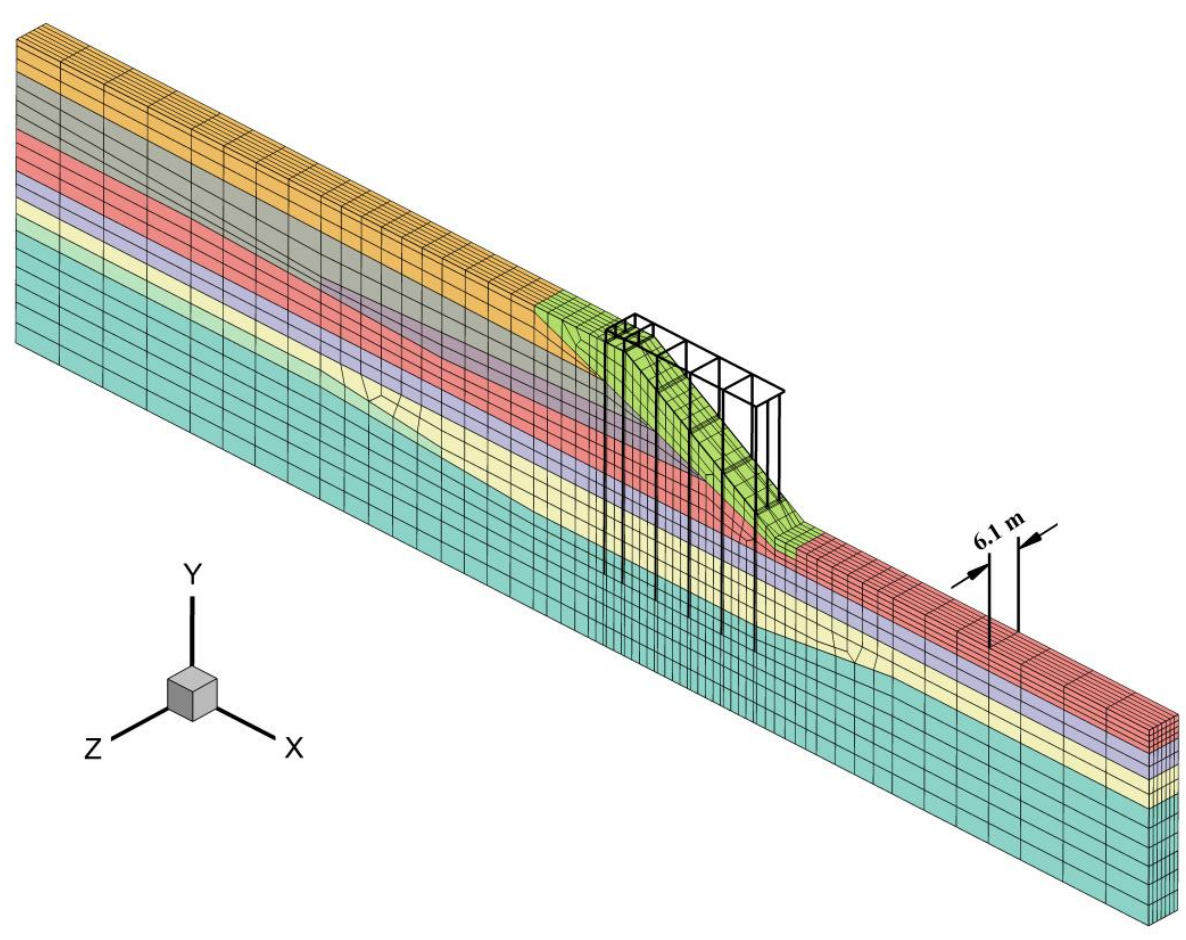

(b) 3D View

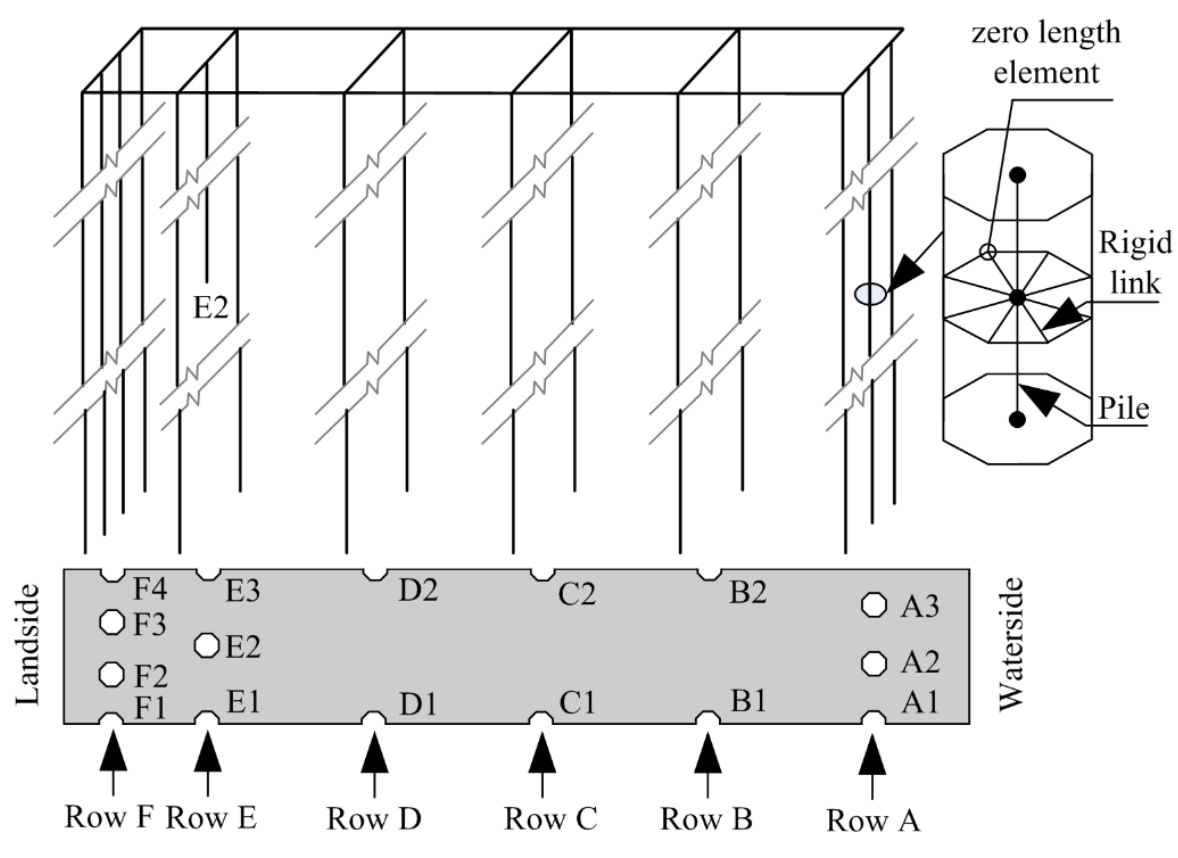

(c) Pile configuration

Fig. 2 Finite element mesh of pile-supported wharf and pile configuration 


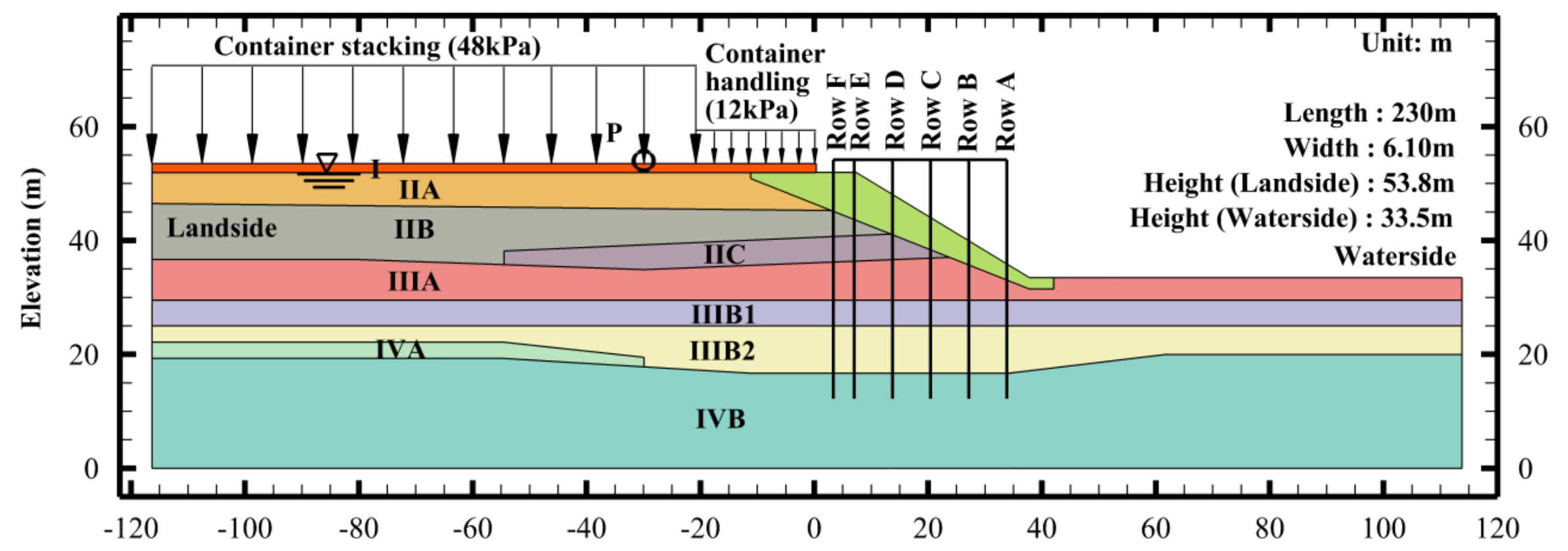

Fig. 3 Layout of pile-supported wharf-ground system for finite element analysis (colors represent different soil layers) 

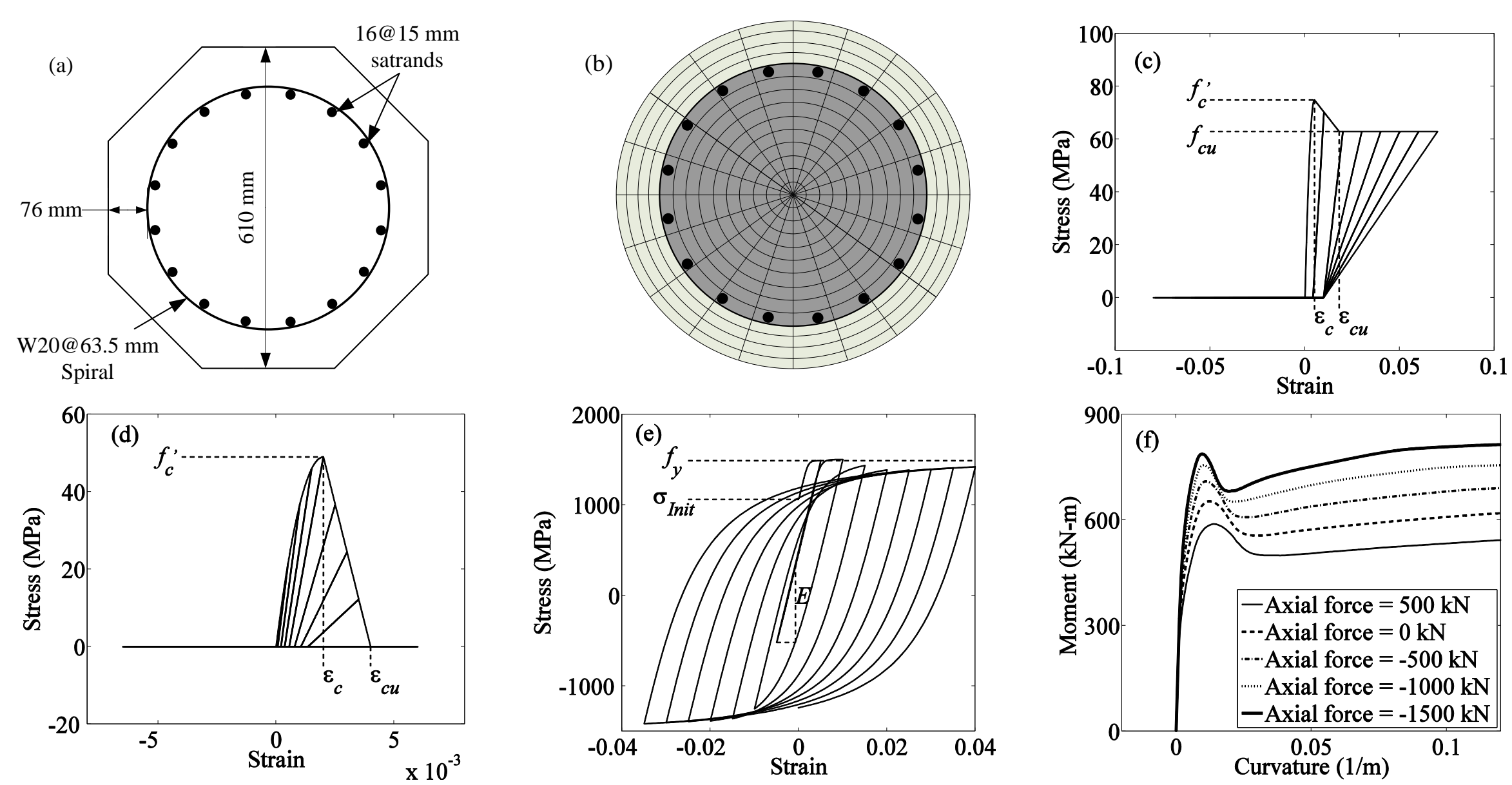

Fig. 4 Prestressed reinforced concrete pile modeling using fiber section beam-column element with uniaxial material constitutive models: (a) pile geometry section; (b) fiber discretization of pile cross section; (c) and (d) Core and cover Concrete01 Kent-Scott-Park model with degraded linear unloading/reloading stiffness; (e) Steel02 Giuffre-Menegotto-Pinto model with isotropic strain hardening and an axial initial stress; (f) Moment-curvature response of prestressed reinforced concrete pile cross section (negative represents compresive axial force; positive represents tensile axial force) 


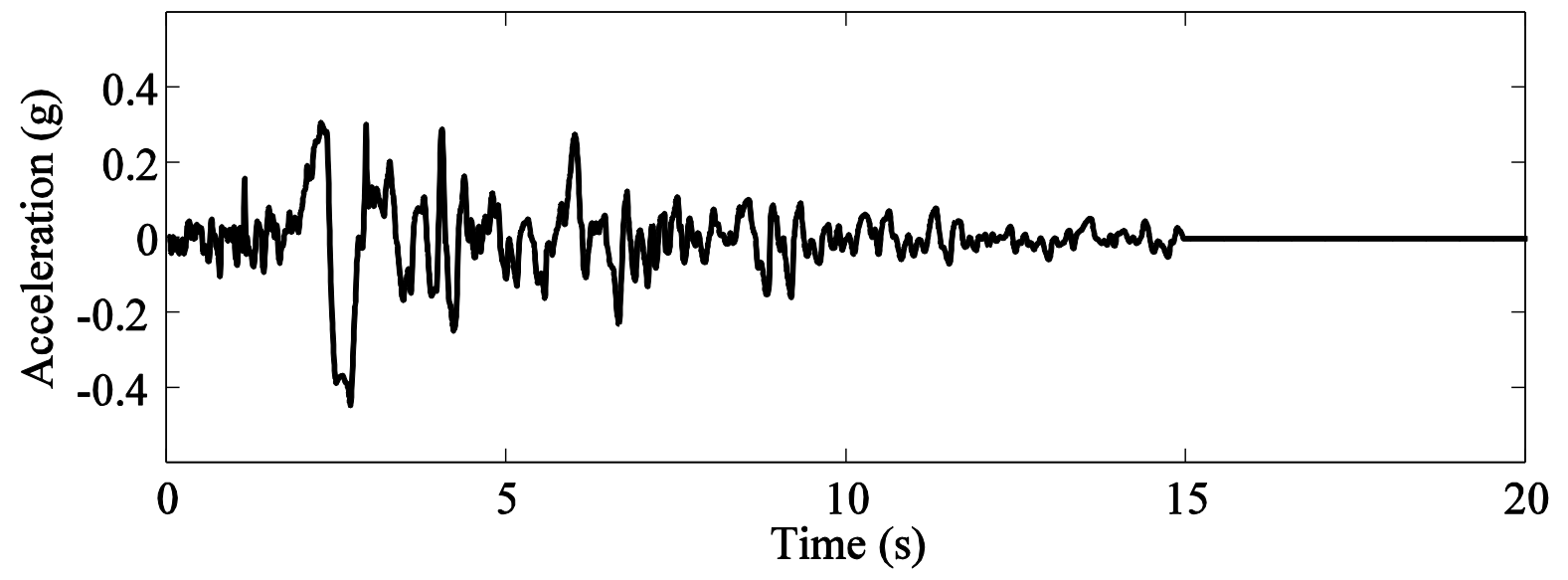

Fig. 5 Base input acceleration 


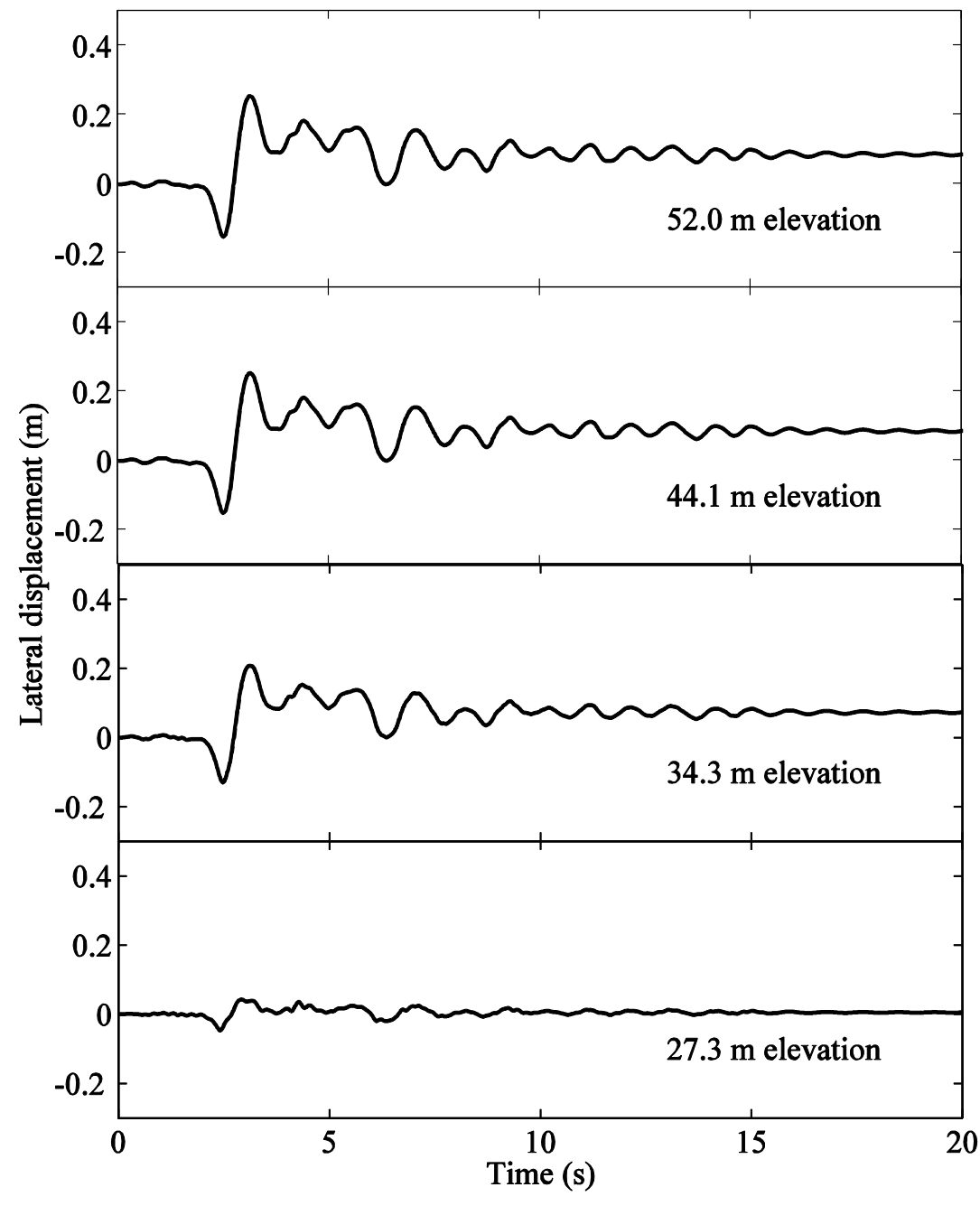

(a) Displacement

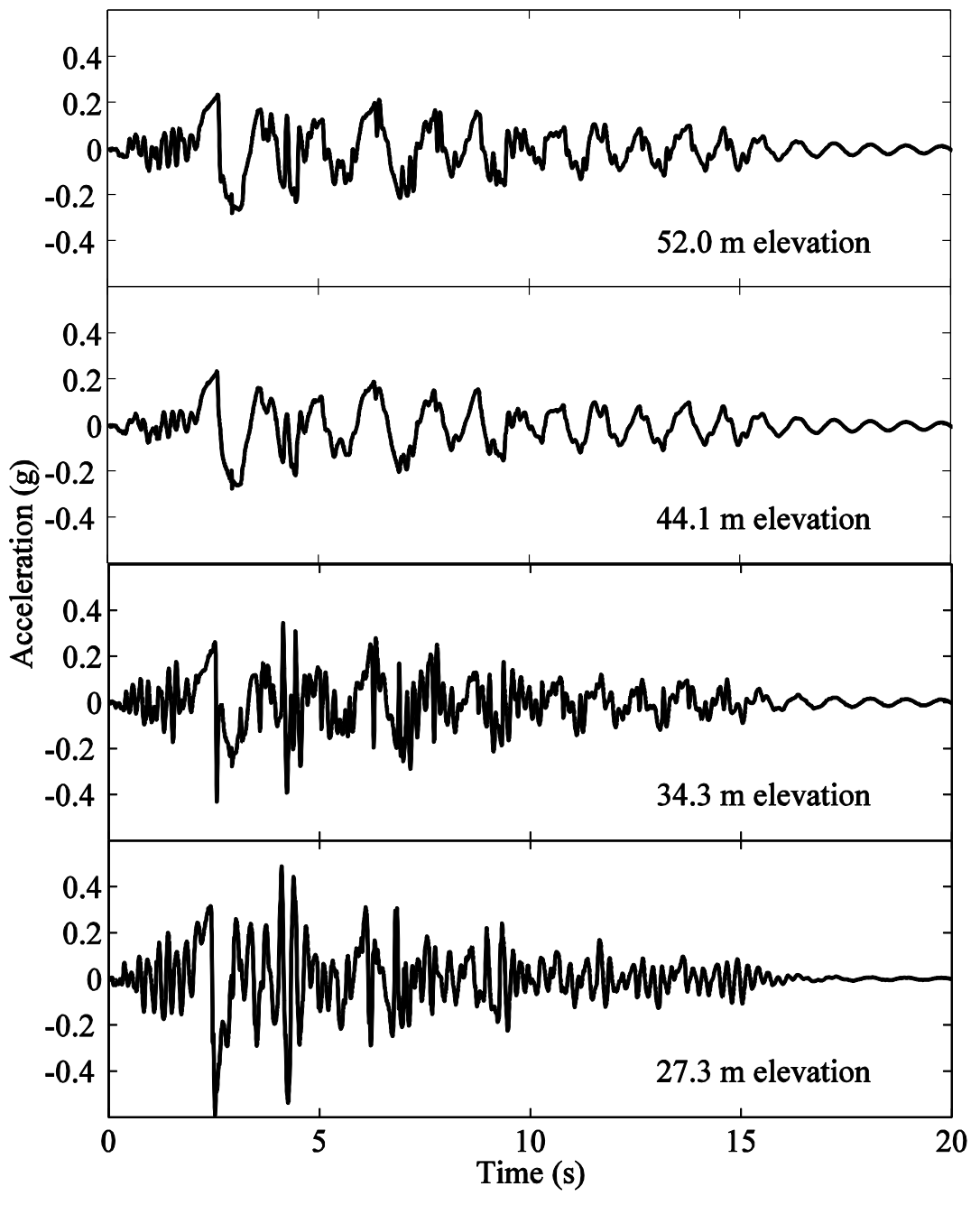

(b) Acceleration

Fig. 6 Landside free field lateral displacement and acceleration time histories 


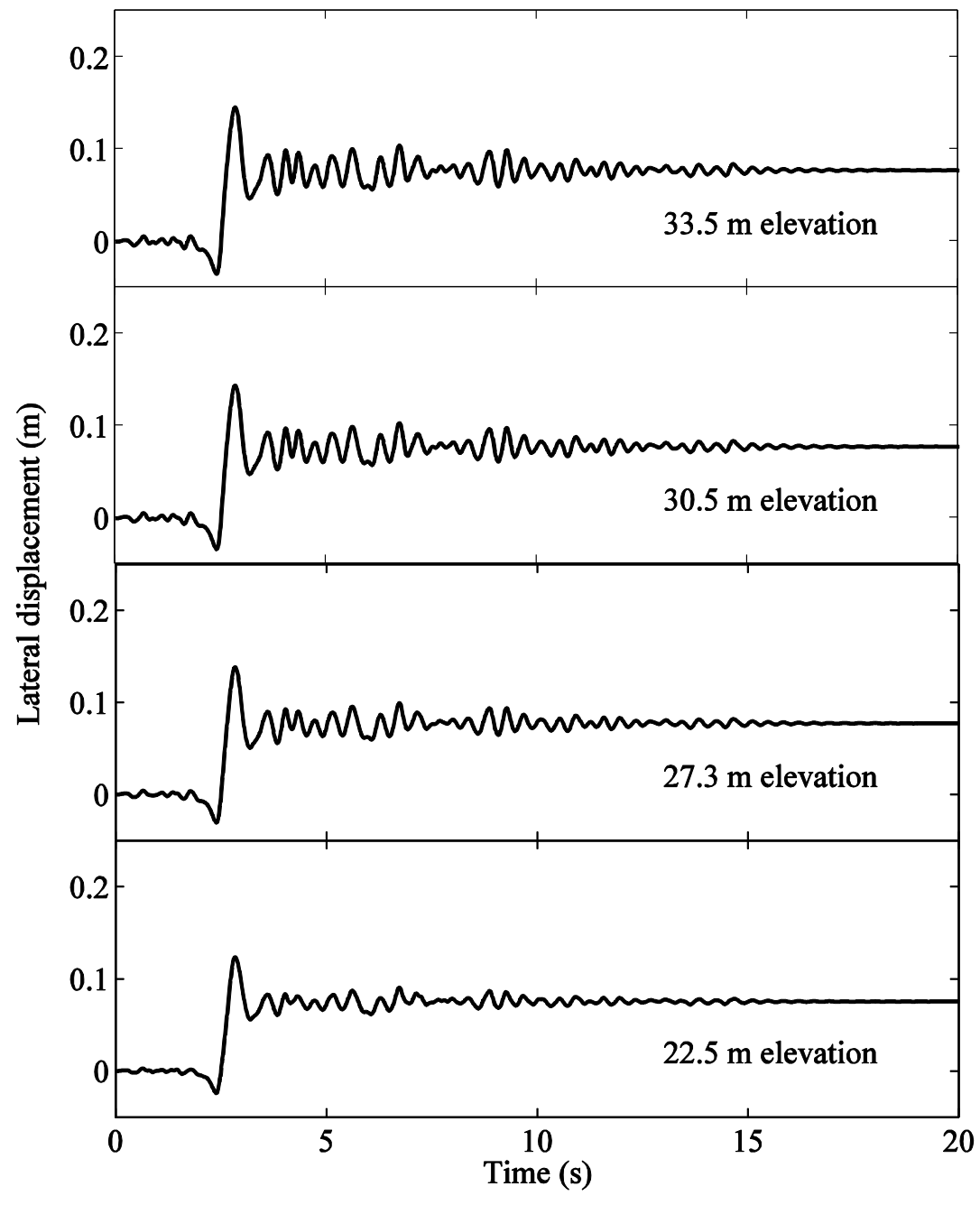

(a) Displacement

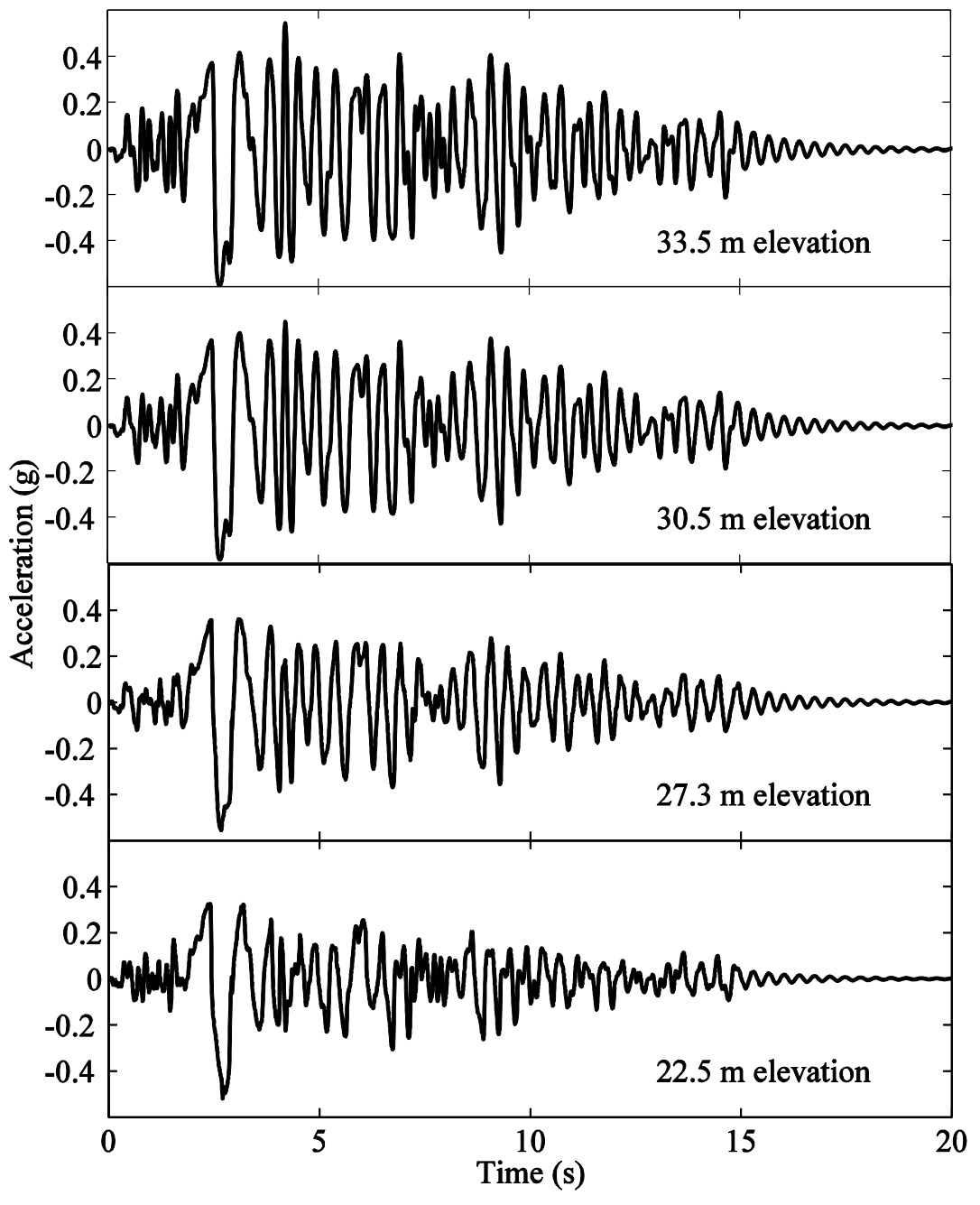

(b) Acceleration

Fig. 7 Waterside free field lateral displacement and acceleration time histories 


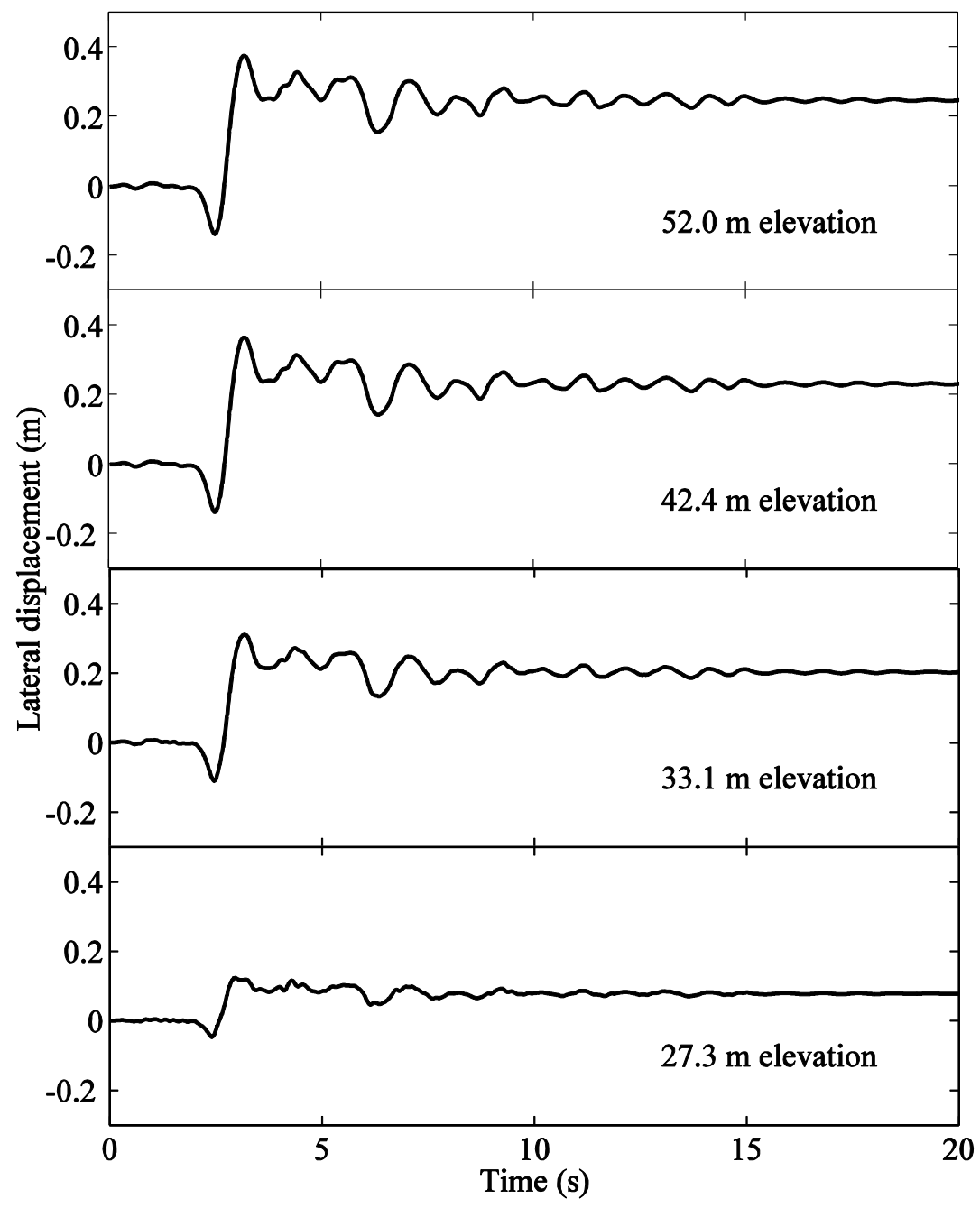

(a) Displacement

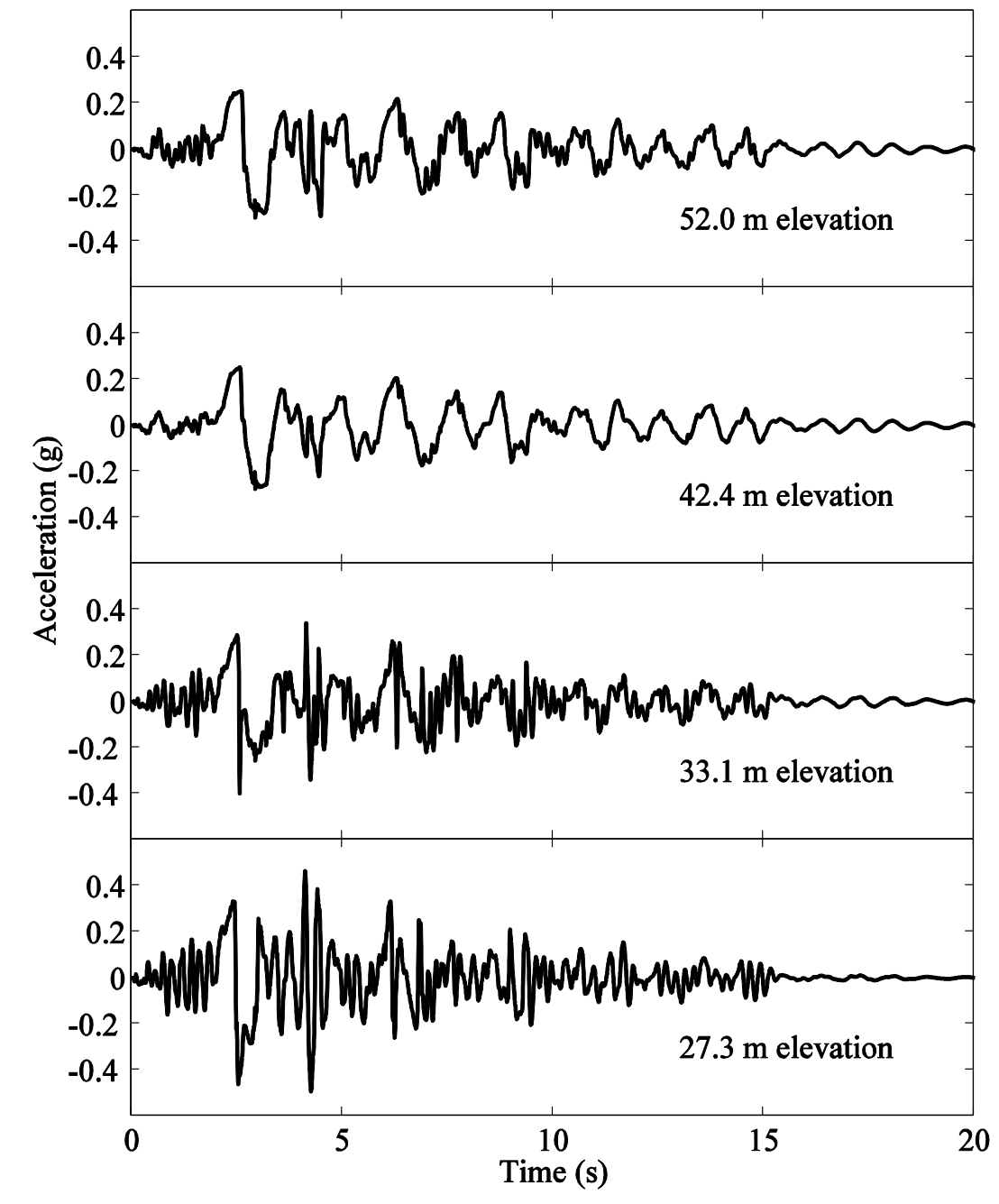

(b) Acceleration

Fig. 8 Lateral displacement and acceleration time histories at Location P of Fig. 3 


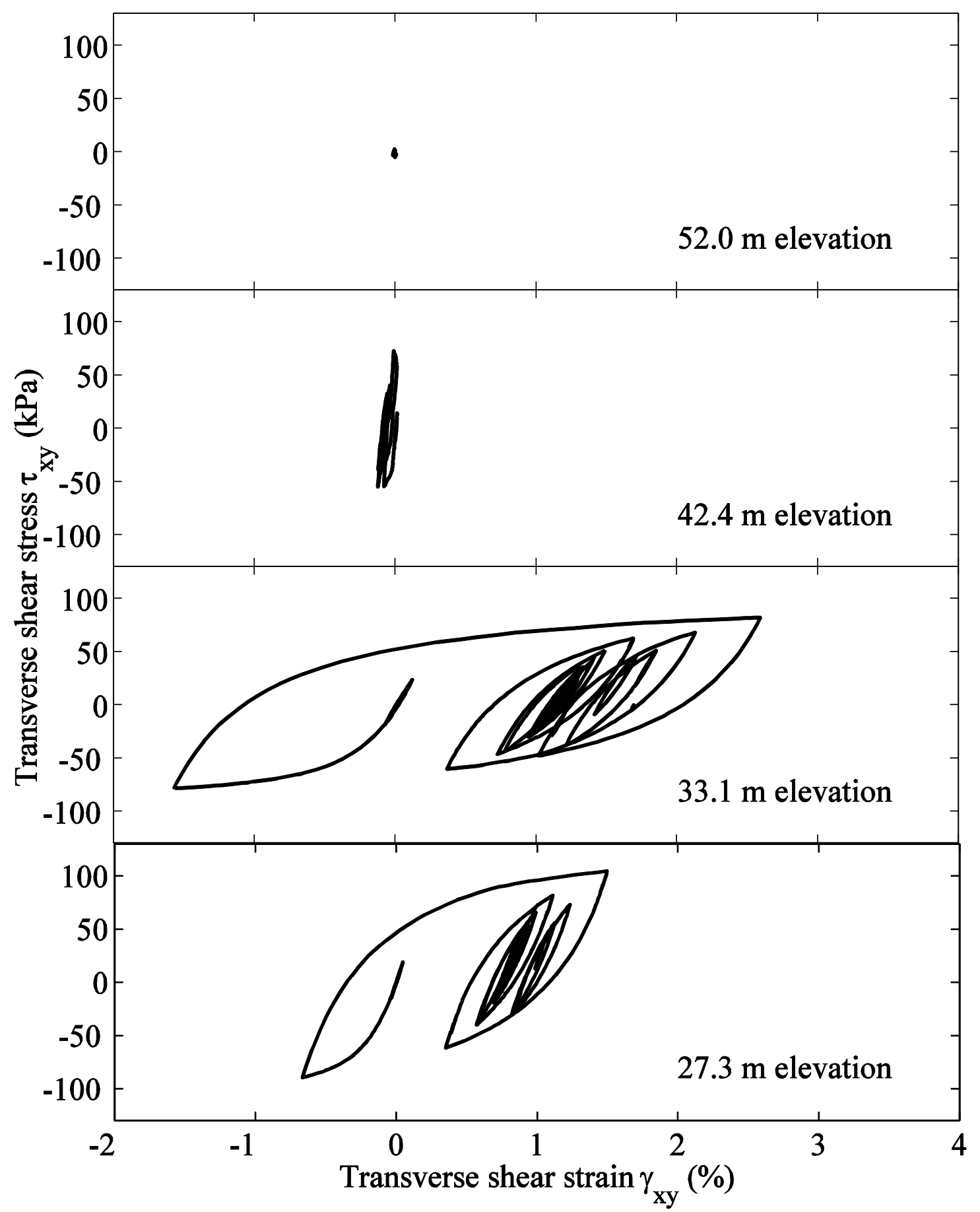

Fig. 9 Shear stress-strain response at Location P of Fig. 3 


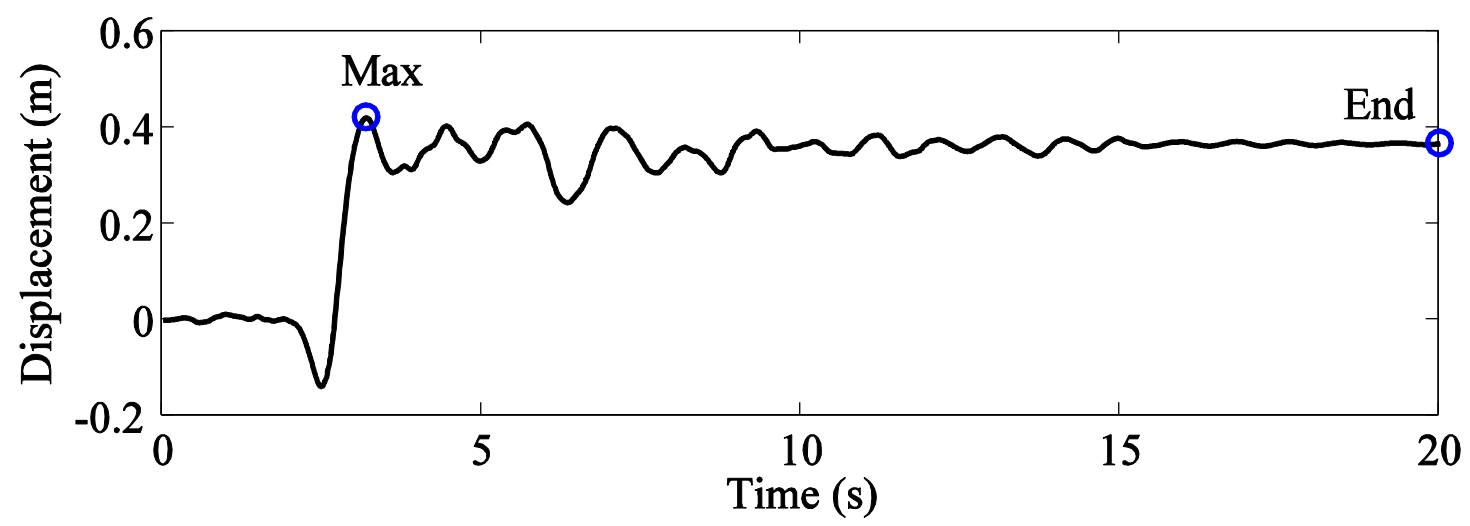

(a) Displacement

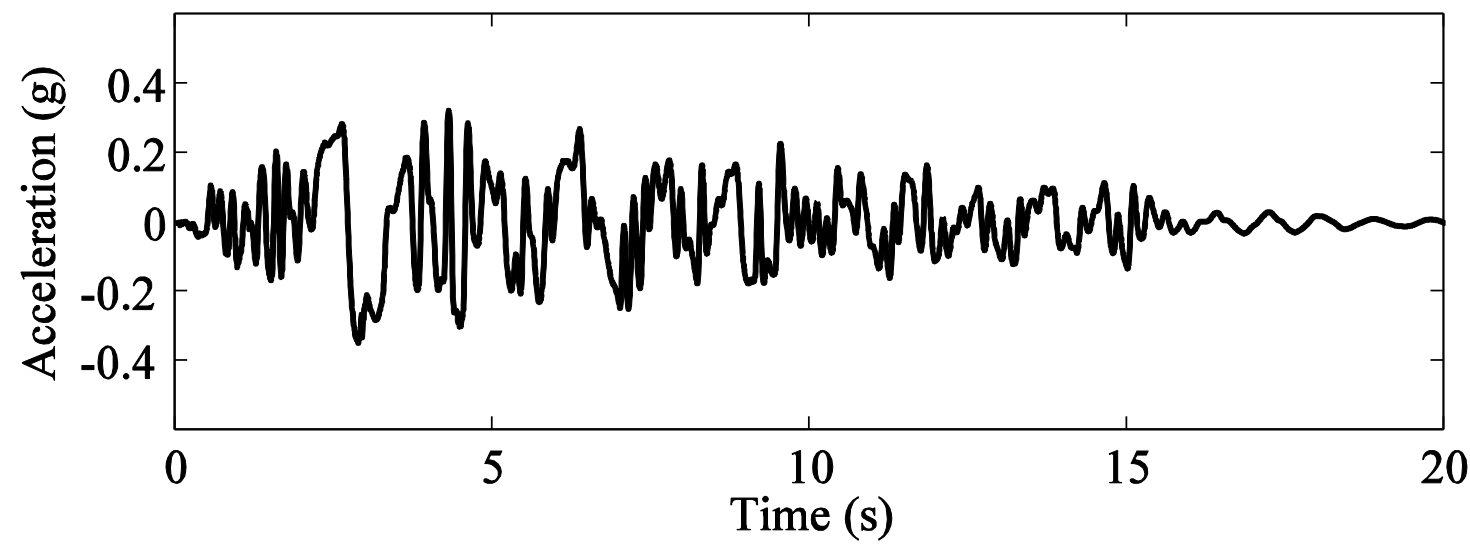

(b) Acceleration

Fig. 10 Deck lateral displacement and acceleration time histories 


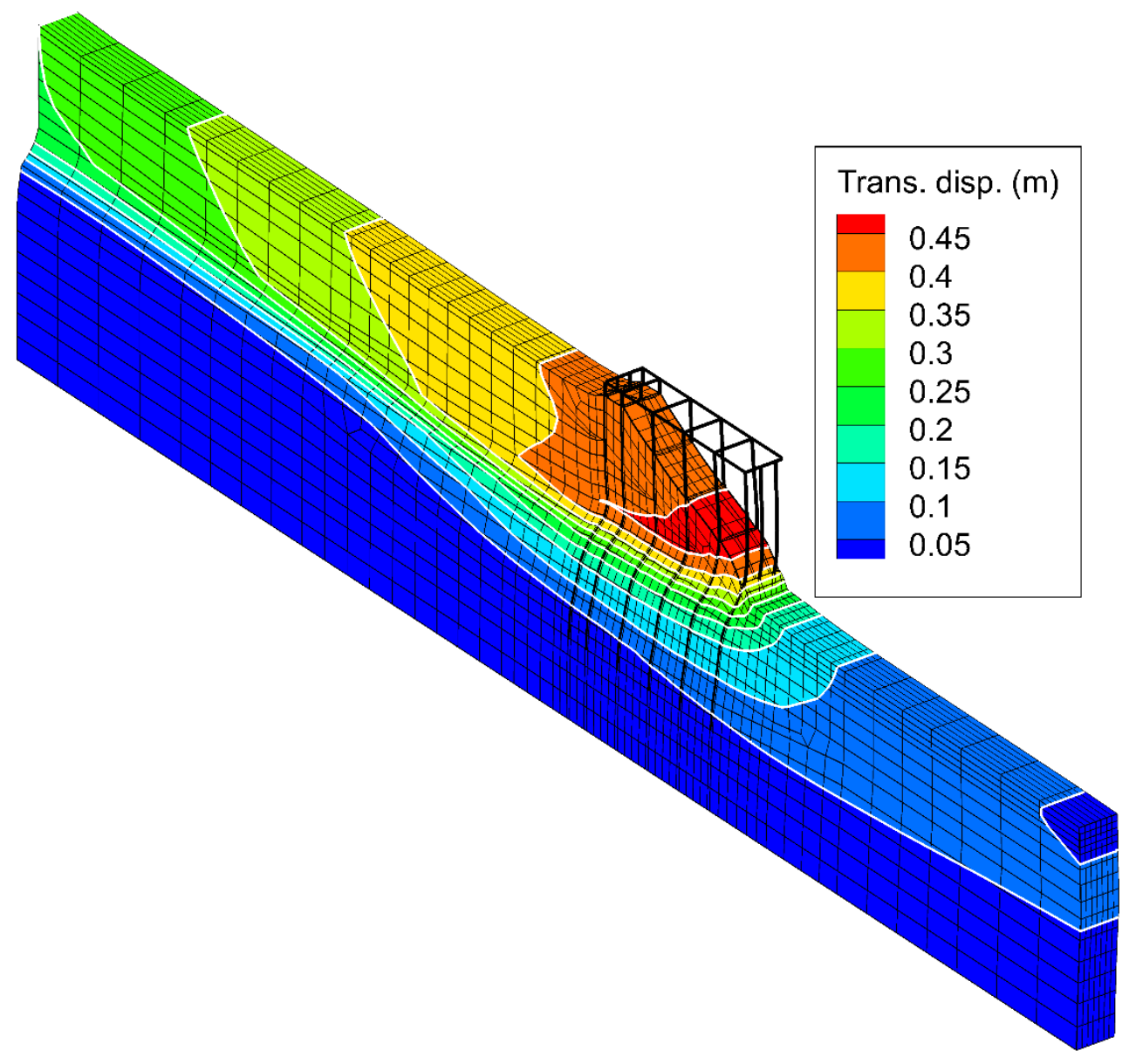

(a) Isometric view

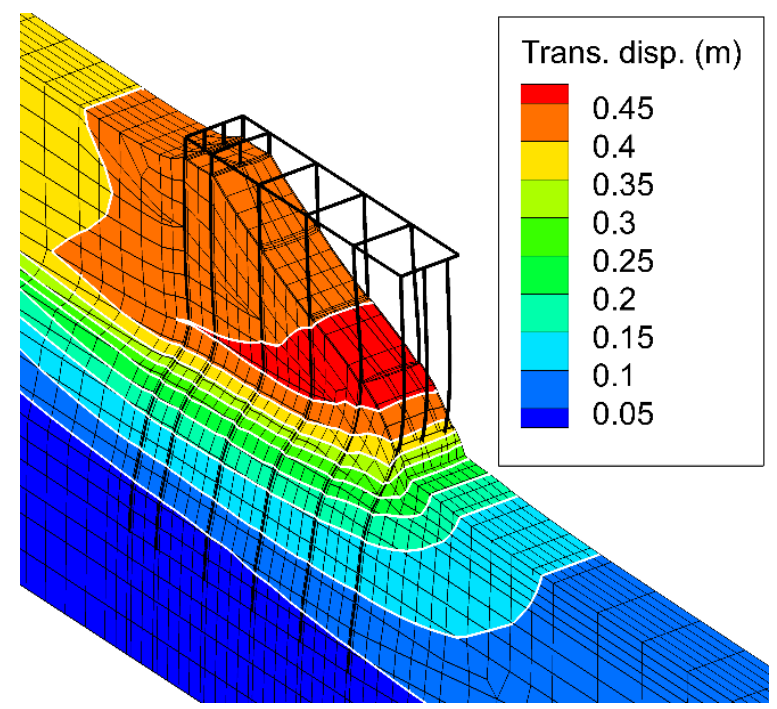

(b) Close-up of wharf with transverse displacement contour

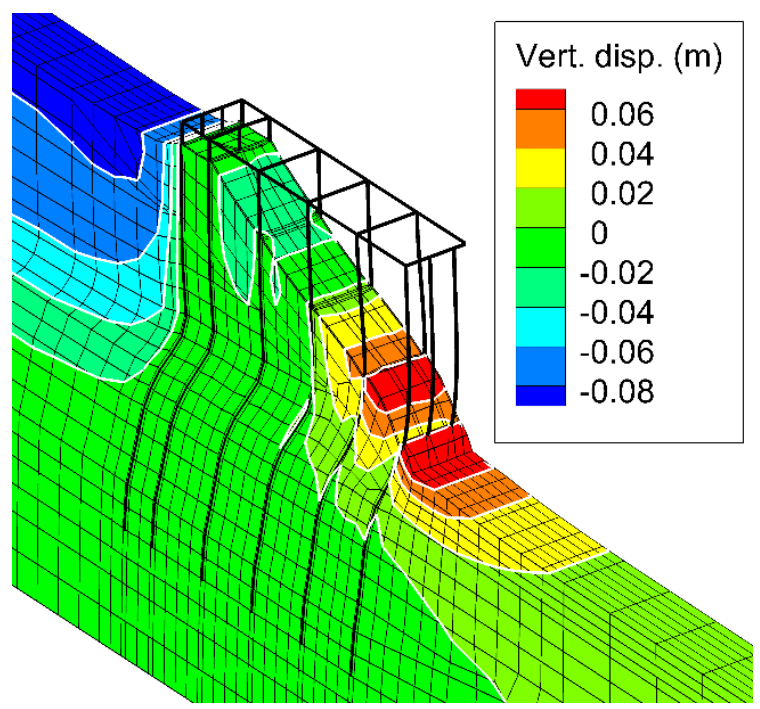

(c) Close-up of wharf with vertical displacement contour

Fig. 11 Deformed mesh at maximum deck displacement (factor of 20, contour fill shows the displacement) 


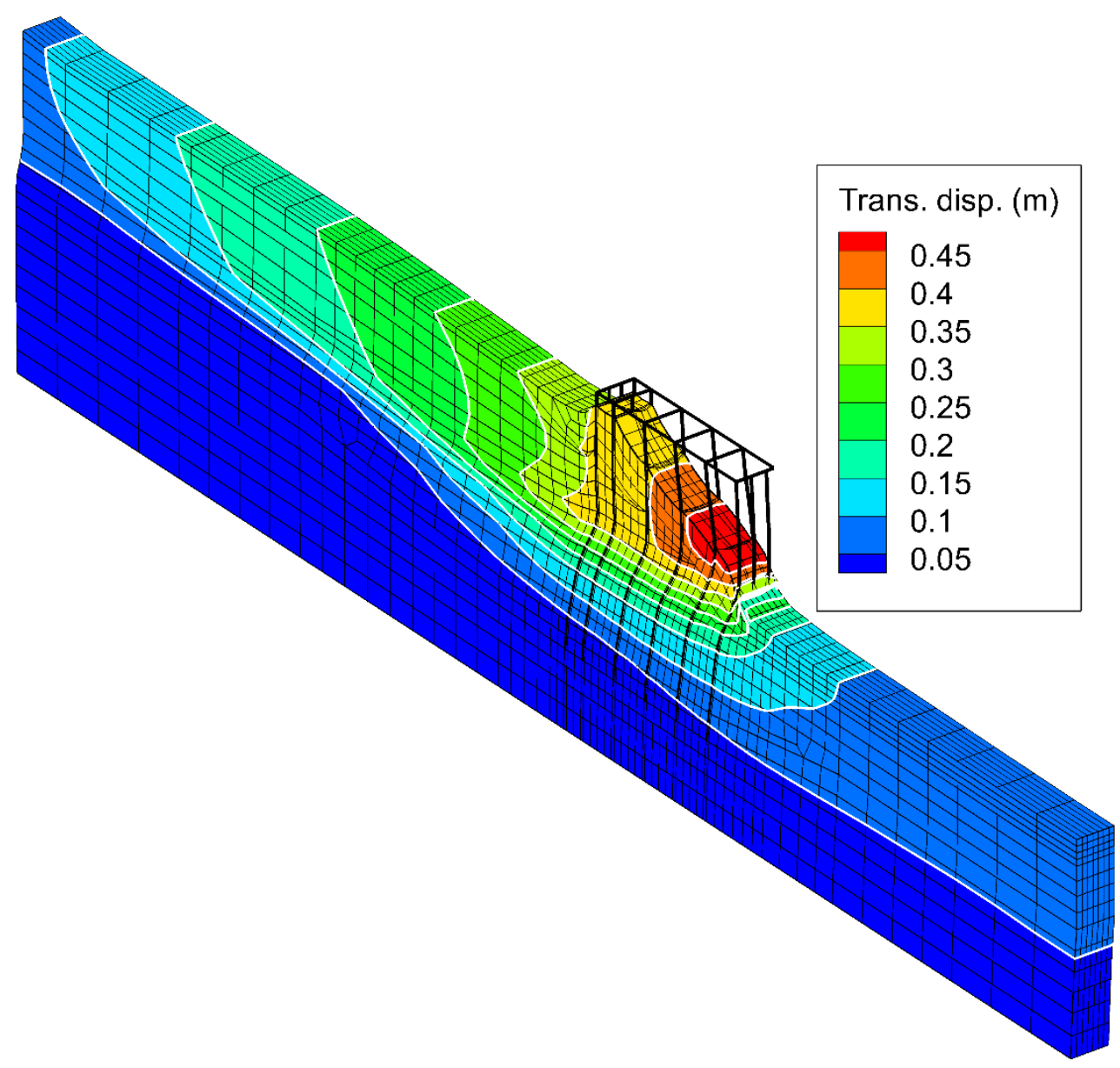

(a) Isometric view

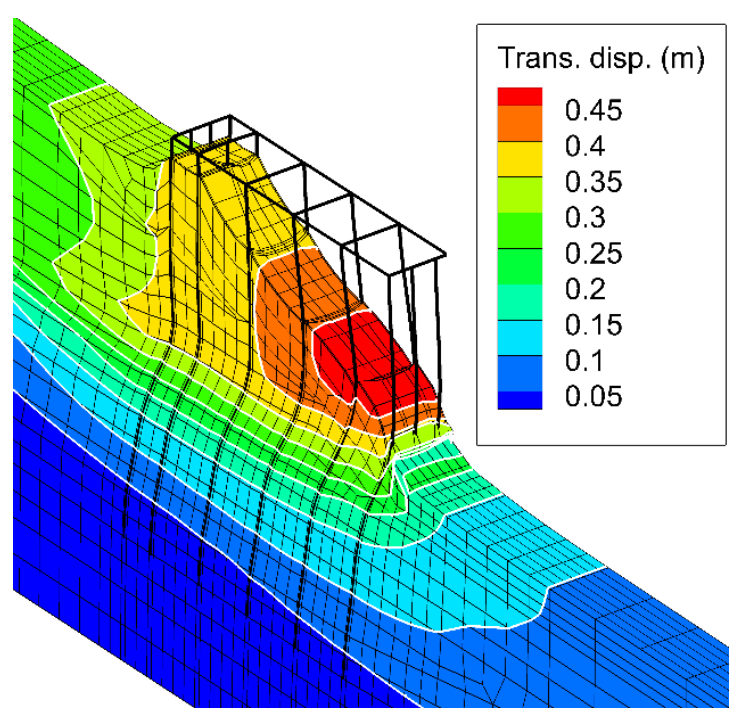

(b) Close-up of wharf with transverse displacement contour

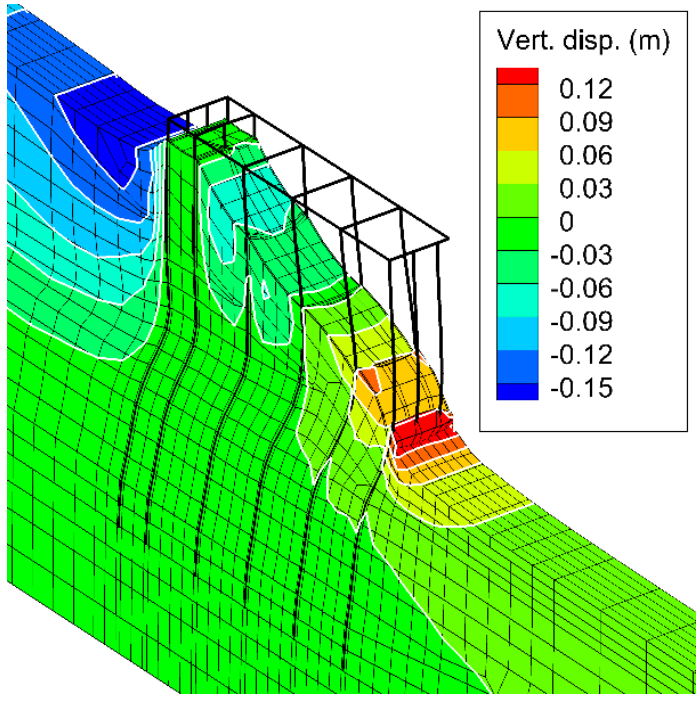

(c) Close-up of wharf with vertical displacement contour

Fig. 12 Deformed mesh at final time step (factor of 20, contour fill shows the displacement) 


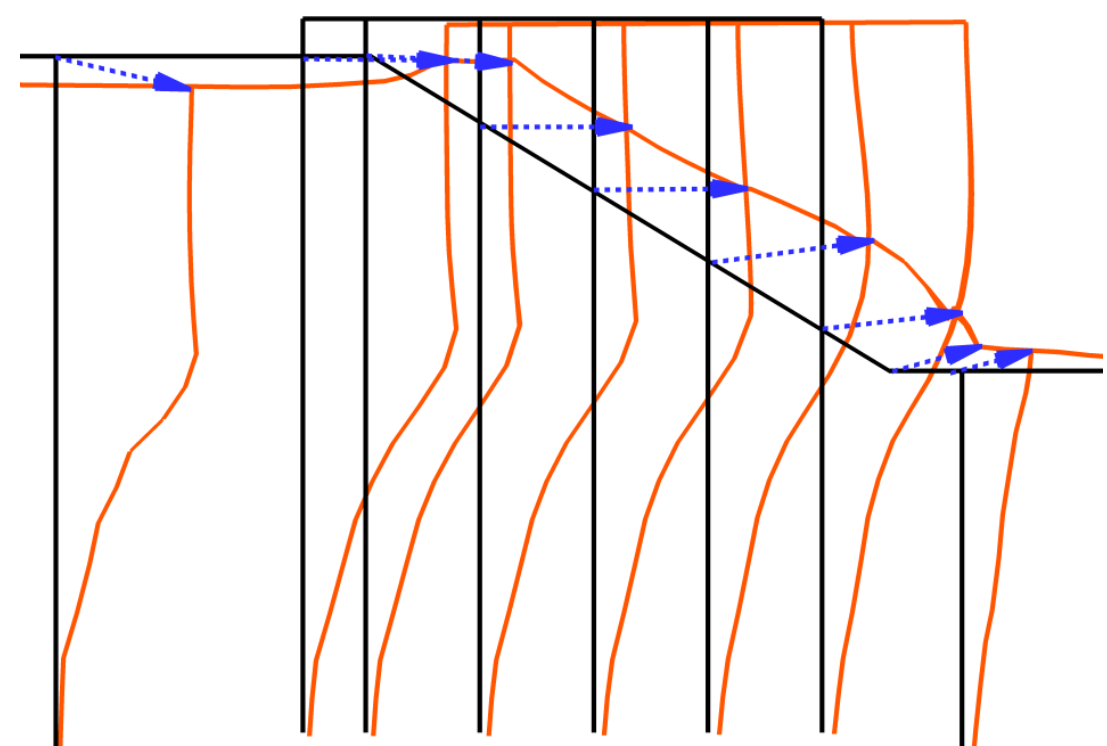

(a) At maximum deck displacement (vertical displacement at top of pile $\mathrm{F} 1=0.018 \mathrm{~m}$ and $\mathrm{A} 1=0.010 \mathrm{~m}$ )

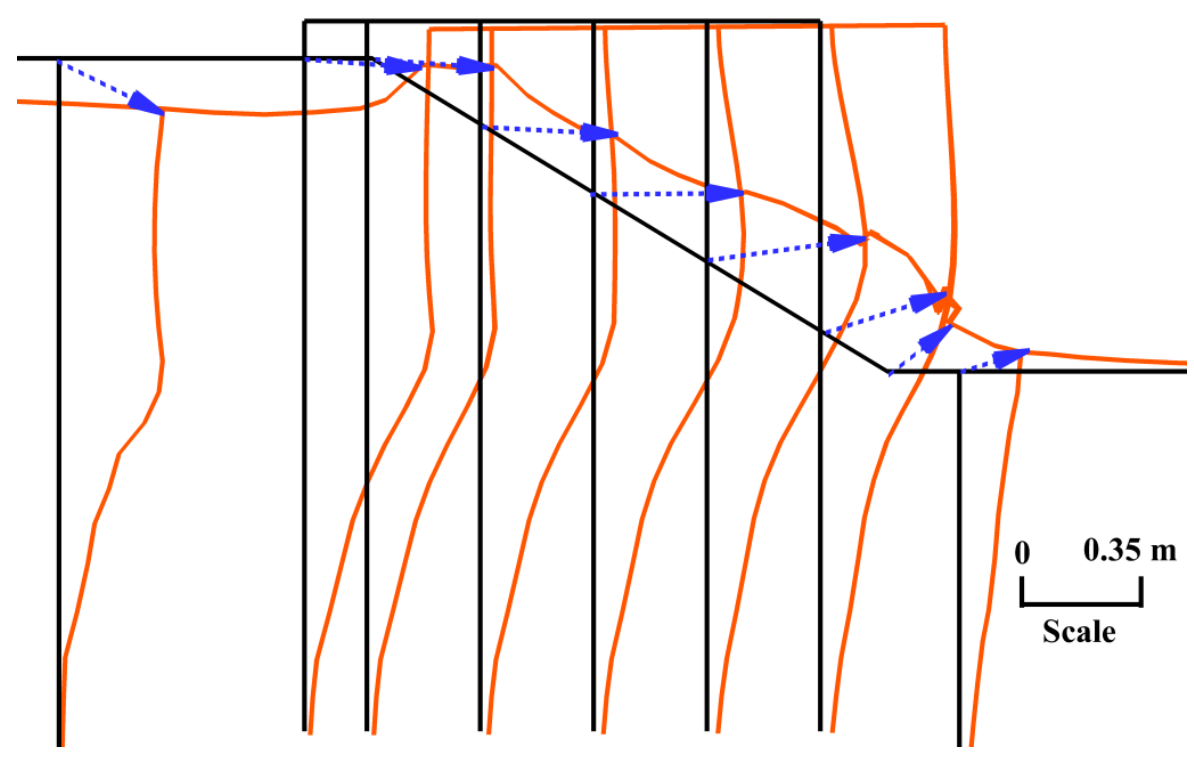

(b) At final time step (vertical displacement at top of pile $\mathrm{F} 1=0.024 \mathrm{~m}$ and $\mathrm{A} 1=0.012 \mathrm{~m}$ )

Fig. 13 Wharf structure deformation at the maximum deck displacement and the final time steps (black lines show original configuration, and red lines show deformed configuration, factor of 20) 

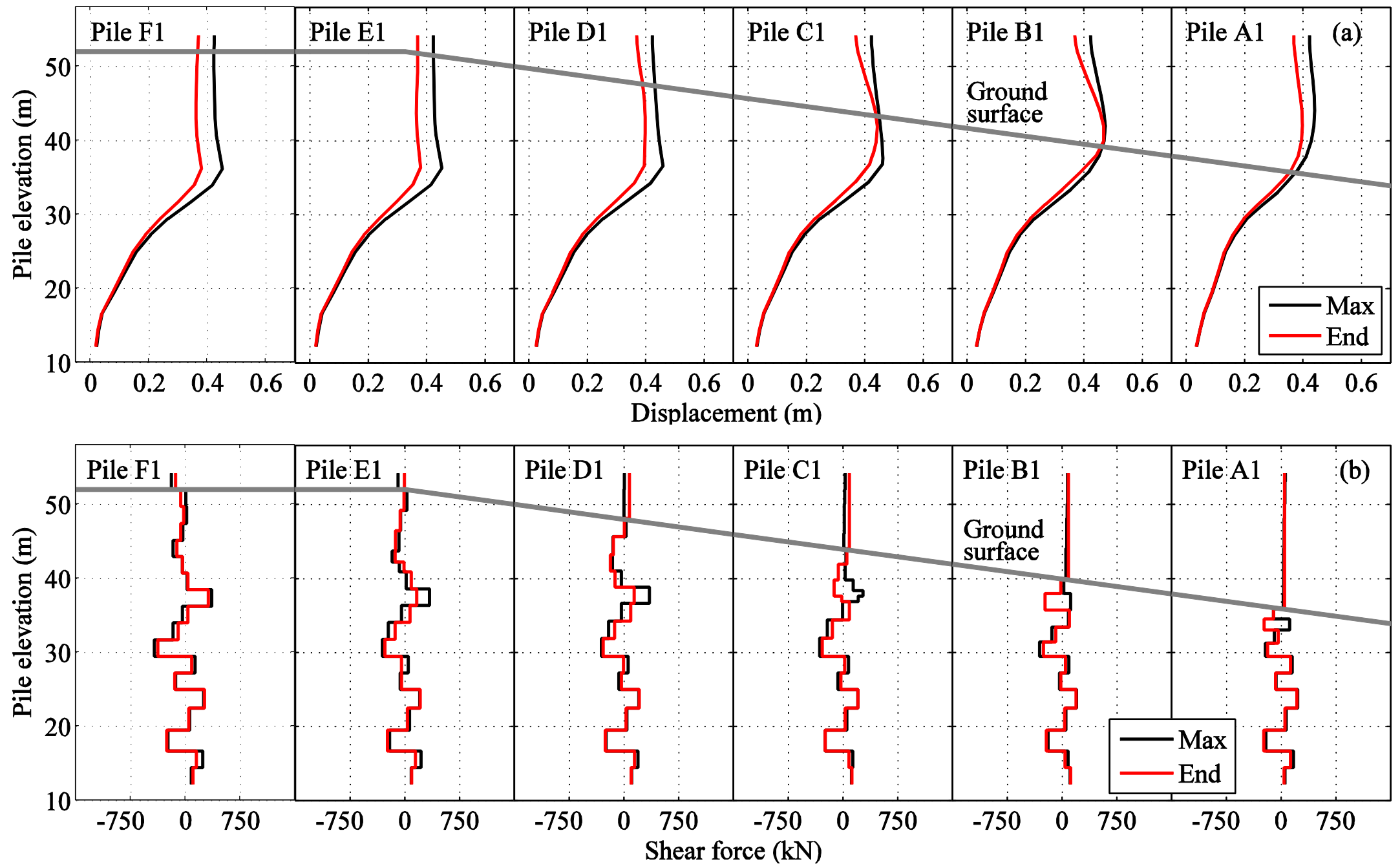

Fig. 14 Lateral pile displacement and shear force response profiles at the maximum deck displacement and the final time steps: (a) Lateral displacement; (b) Shear force 

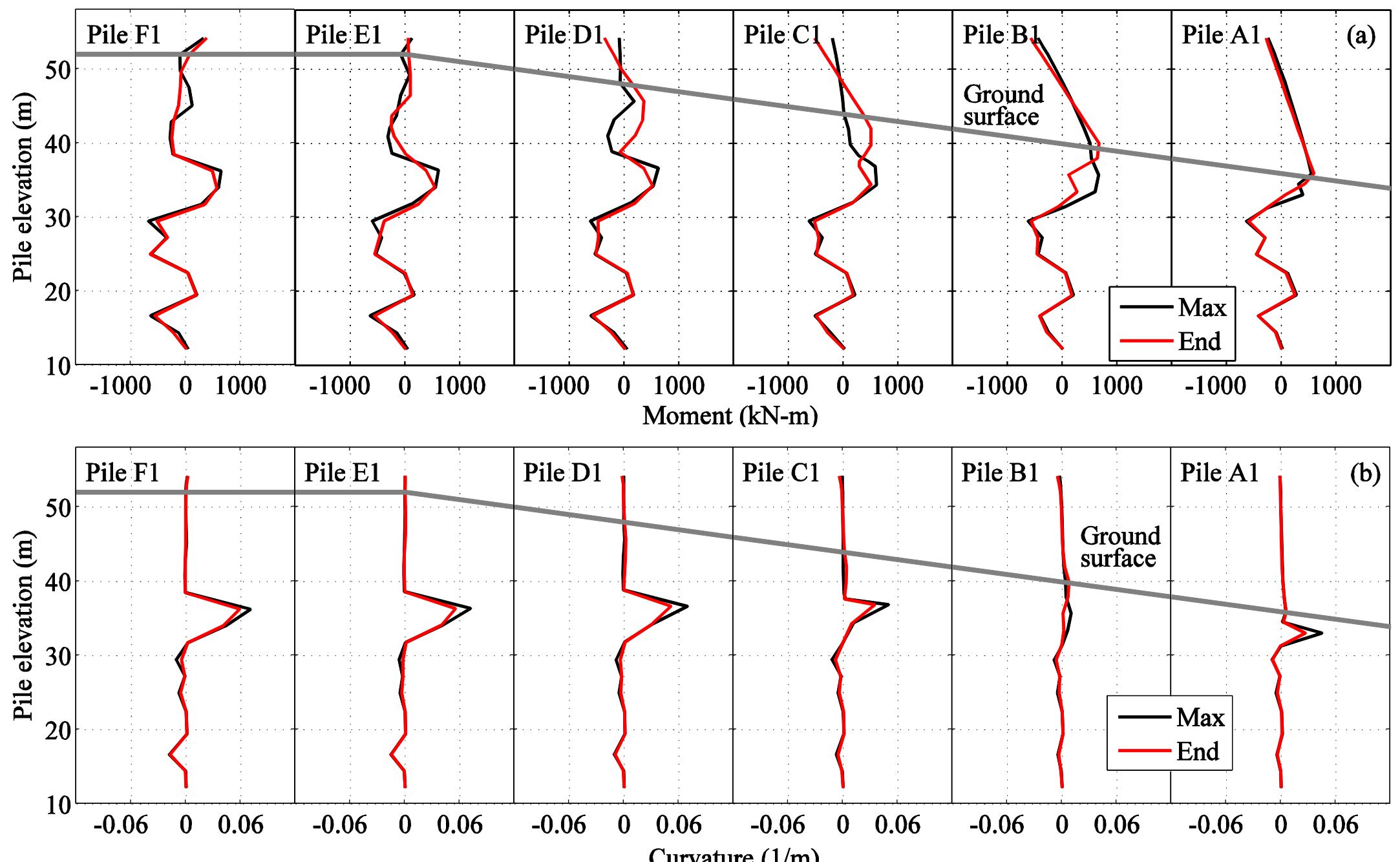

Fig. 15 Pile bending moment and curvature response profiles at the maximum deck displacement and the final time steps: (a) Bending moment;

(b) Curvature 

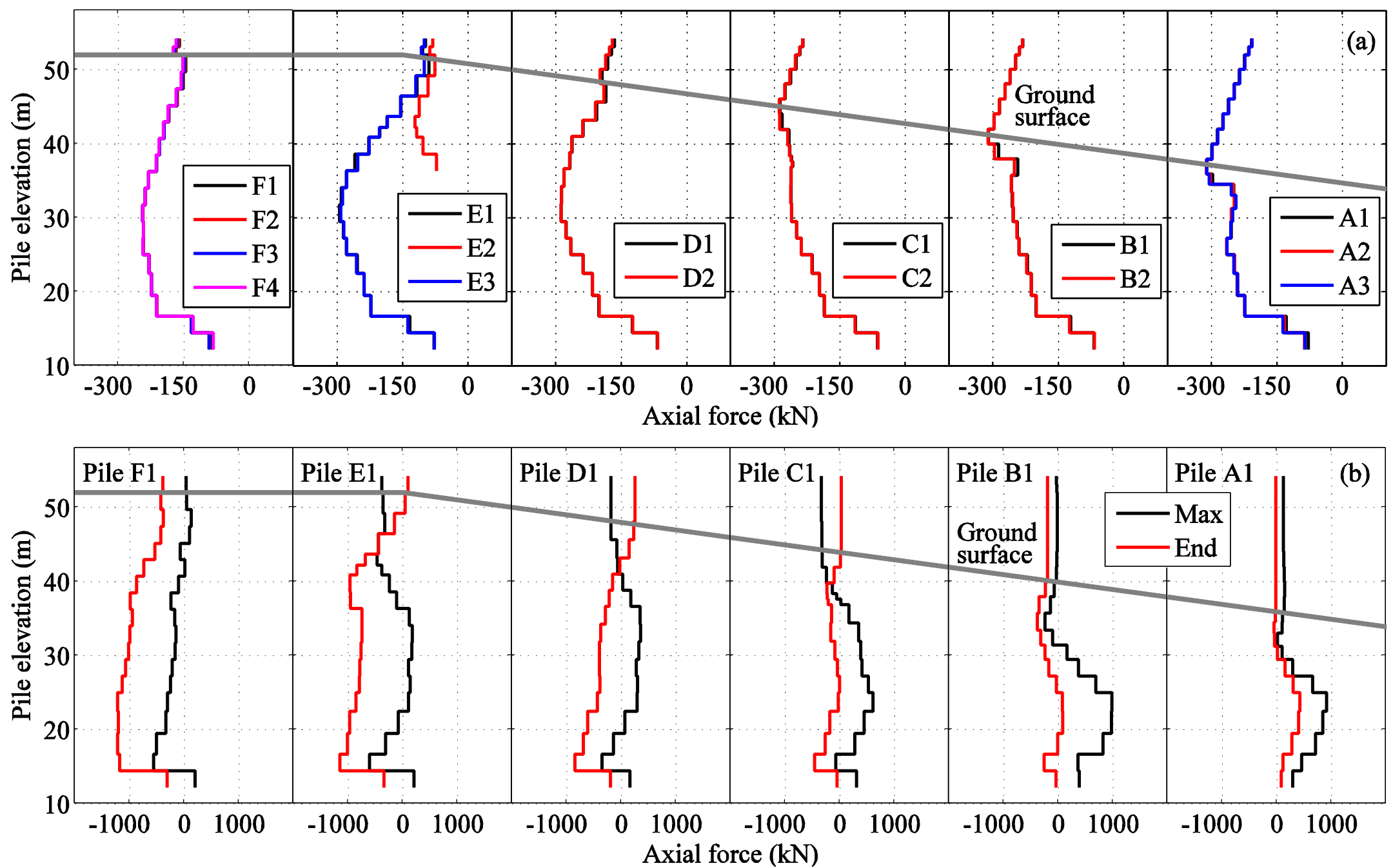

Fig. 16 Pile axial force response profiles (a) Before shaking; (b) Change due to the shaking event (maximum deck displacement and final time steps) 

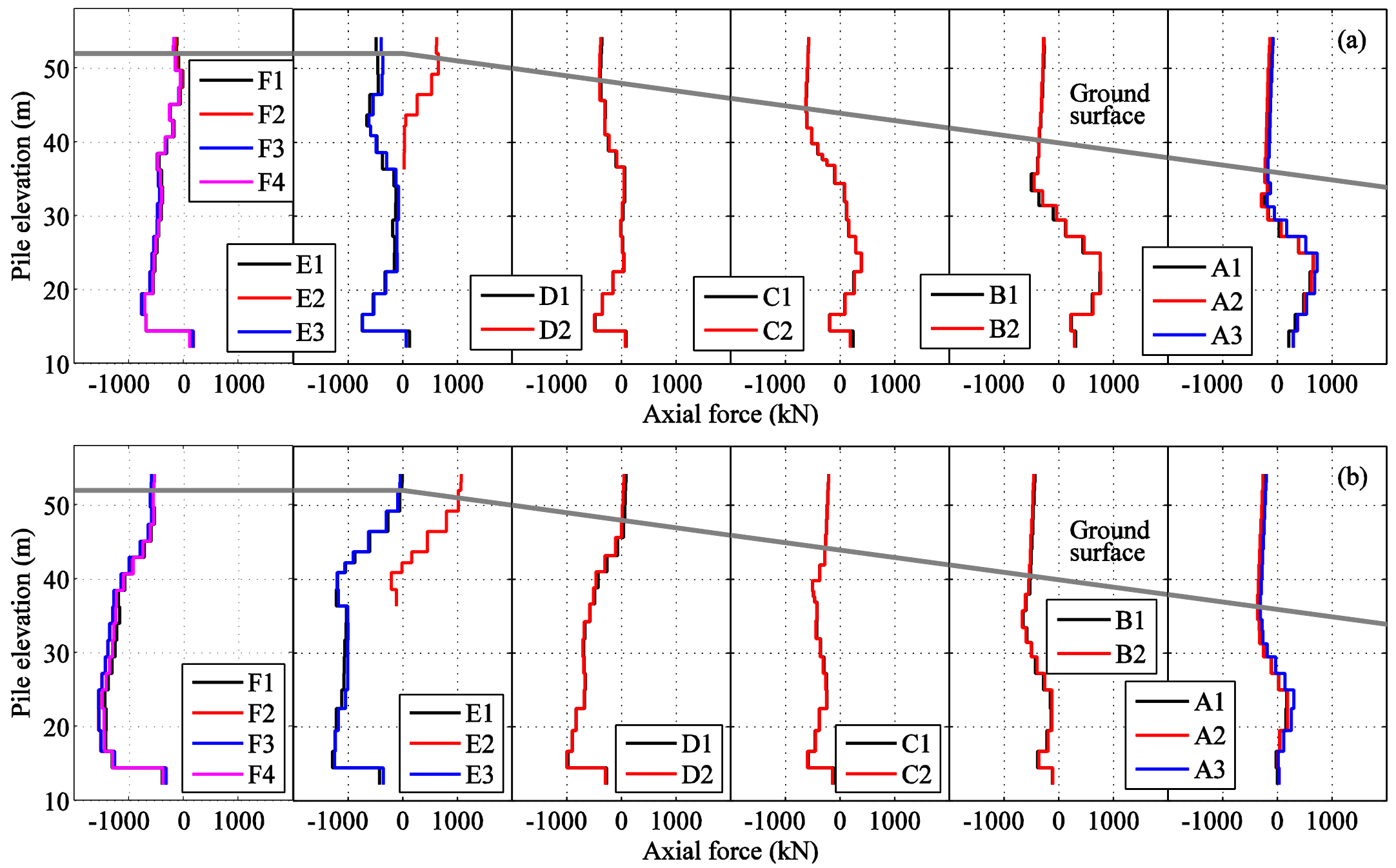

Fig. 17 Pile axial force response profiles: (a) Maximum deck displacement time step; (b) Final time step 

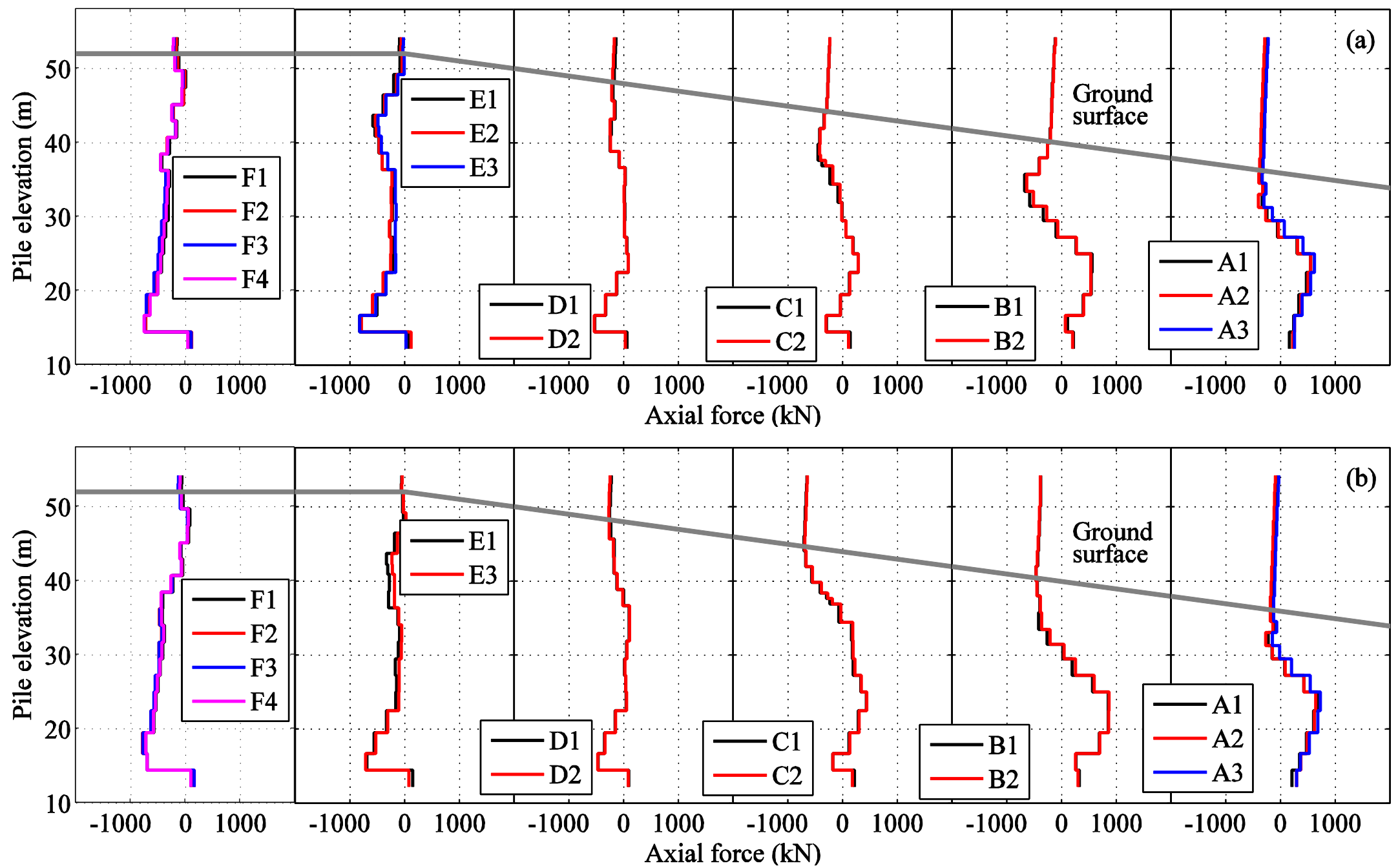

Fig. 18 Pile axial force response profiles at the maximum deck displacement time step: (a) Long pile E2 (case A); (b) Without pile E2 (case B) 